\title{
The VENUS cabled observatory as a method to observe fish behaviour and species assemblages in a hypoxic fjord, Saanich Inlet (British Columbia, Canada)
}

\author{
Matabos Marjolaine ${ }^{1,2,{ }^{*}}$, Piechaud Nils ${ }^{2}$, De Montigny Francois ${ }^{1}$, Sarradin Pierre-Marie ${ }^{2}$, \\ Sarrazin Jozee ${ }^{2}$
}

${ }^{1}$ Univ Victoria, Sch Earth \& Ocean Sci, Victoria, BC V8W 3V6, Canada.

2 IFREMER, EDROME, REM, EEP,Lab Environm Profond, F-29280 Plouzane, France.

Corresponding author: Marjolaine Matabos, email address : Mariolaine.Matabos@ifremer.fr

\begin{abstract}
:
Studies reporting processes that may shape marine benthic communities under the seasonal scale are rare at depths $>50 \mathrm{~m}$. In this study, the use of the VENUS multidisciplinary cabled observatory provided 2-month high-resolution data combining quantitative biology and environmental data in Saanich Inlet, a seasonally hypoxic fjord located on Vancouver Island (British Columbia, Canada). An ecological module equipped with a camera acquired a 3 min video clip every half hour during 2 months at $97 \mathrm{~m}$ depth in the oxygen fluctuation zone of the fjord. Results highlighted the role of the tidal cycle on species activity rhythms and confirmed the influence of oxygen fluctuations on benthic assemblage structure and species behaviour. However, environmental variables considered only explained a small proportion of the total variance in species data. This study demonstrates how seafloor observatories can be used to study species behaviour and community dynamics in relation to abiotic conditions by providing continuous access to multidisciplinary data.
\end{abstract}

\section{Résumé :}

Les études sur les processus qui influencent la structure des communautés marines benthiques profondes $(>50 \mathrm{~m})$ à des échelles inférieures aux saisons sont rares. Dans cet article, l'utilisation de l'observatoire multidisciplinaire câblé VENUS a fourni 2 mois de données haute fréquence combinant des données quantitatives biologiques et environnementales dans le Saanich Inlet, un fjord hypoxique saisonnier localisé sur l'île de Vancouver (Colombie-Britannique, Canada). Un module écologique a enregistré des séquences vidéo de 3 min toutes les demi-heures pendant 2 mois à $97 \mathrm{~m}$ de profondeur dans la zone de fluctuation d'oxygène. Les résultats ont permis de mettre en évidence le rôle des cycles de marées sur l'activité rythmique des espèces et ont confirmé le rôle des variations temporelles des concentrations en oxygène sur la structure des assemblages faunistiques et le comportement des espèces benthiques. Cependant, les variables environnementales considérées expliquent une faible proportion de la variance. Cette étude démontre comment les observatoires sous-marins permettent d'étudier le comportement des espèces et la dynamique des communautés benthiques en relation avec les facteurs abiotiques, en fournissant un accès continu à des données multidisciplinaires. 


\section{INTRODUCTION}

Understanding processes controlling community dynamics is a core question in ecology. The structure of marine benthic communities is controlled over multiple interrelated spatial and temporal scales (Levin 1992; Brewin et al. 2011). While seasonal patterns and inter-annual variations have been widely studied using ship-based sampling (e.g. Nordberg 2001; Blanchard et al. 2010; Glover et al. 2010), we have a limited understanding of small-scale variability of benthic communities in marine environments, especially at depths. Furthermore, ecological observations resulting from punctual sampling often neglect biological rhythm frequencies misleading our understanding of community and ecosystem dynamics (Morgan 2004). On a daily scale, cyclic processes such as day/night light intensity and tidal variations can modulate species activity and behaviour and thus influence community dynamics (Aguzzi and Company 2010; Aguzzi et al. 2011). Biological rhythm modulation by natural cycles is an important aspect of marine biology (Naylor 2005; Aguzzi and Company 2010) and is receiving increasing attention in a wide range of marine environments (Aguzzi et al. 2011, 2012; Cuvelier et al. in press). While in the photic zone, the circadian day/night cycle is a strong modulation of species activity, in depths where light does not penetrate, internal tides and inertial currents dominate (review in Aguzzi et al. 2011).

Chronobiologists traditionally used laboratory approaches to study physiological processes in relation to endogenous circadian oscillators (e.g. for decapods see review in Aguzzi and Company 2010); it is however important to consider activity rhythms in an ecological context where complex interactions among organisms and their environment occur (Marques and Waterhouse 2004; Matabos et al. 2011). For example, day-night based activity rhythms in decapods can be masked by competition for substrata (Aguzzi et al. 2009), food availability (Fernandéz de Miguel and Aréchiga 1994) and dissolved oxygen fluctuations (e.g. Schurmann et al. 1998; Matabos et al. 2011). On the other hand, stochastic events such as storms, sediment resuspension and water renewal processes, can generate perturbations by changing current 
regimes or biological activity which will in turn create discontinuities in regular cycles (Yahel et al. 2008; Matabos et al. 2011).

To date, due to technological limitations in sampling deep areas, studies reporting processes that may shape benthic communities at sub-seasonal scale are rare in all environments, including fjords (e.g. Matabos et al. 2012). Long-term continuous observations represent an information gap in our better understanding of the relative influence of biotic and abiotic factors acting at different temporal scales on benthic community dynamics. The use of multi-disciplinary cabled observatories offers the opportunity to sample at high-resolution and conduct integrated studies at the ecosystem level by combining quantitative biology and environmental data (Tunnicliffe et al. 2003).

Cabled observatories provide power and communication to instruments deployed on the seafloor through cables that connect instrument arrays to shore. The VENUS cabled network allows remote, continuous, and real-time observation of plankton and seafloor organisms together with physical and chemical variables in Saanich Inlet, an intermittently anoxic fjord, located on southern Vancouver Island (British Columbia, Canada; Tunnicliffe et al. 2003). A shallow sill $(70 \mathrm{~m})$ at the mouth of Saanich Inlet isolates the deep basin $(215 \mathrm{~m})$ that is subject to a high vertical flux of organic matter (Herlinveaux 1962; Cohen 1978; Timothy and Soon 2001). During spring tides, the surface waters of the Inlet flow seaward and are replaced by nutrientrich sub-surface waters from outside of the fjord (Gargett 2003). This supply of nutrients maintains high productivity throughout much of the fjord during spring and summer months, leading to anoxia in the deep basin. Deep-water renewal occurs during the fall when dense oxygenated intermediate water masses formed in the adjacent Haro Strait enter the Inlet (Anderson and Devol 1973). The benthic community inhabiting the fluctuation zone is well adapted to low oxygen concentrations (Tunnicliffe 1981; Burd and Brinkhurst 1984) where they take advantage of higher food availability and low predation rates (Matabos et al. 2012). The lower limit of the photic zone (1\% incident radiation) in Saanich Inlet is consistently at ca. $20 \mathrm{~m}$ 
depth (Grundle et al. 2009). All known processes in Saanich Inlet appeared to structure benthic communities at their respective temporal scales, including fortnightly (Matabos et al. 2012) and semi-diurnal tidal signals (Matabos et al. 2011). However, in the latter study, the short timeseries, combined with the occurrence of an oxygen intrusion during the study period, did not allow a clear detection of a tidal rhythm in species behaviour; a longer time-series was needed to confirm the patterns observed. While Saanich Inlet is a long-time well-studied fjord, the VENUS observatory supports the investigation of small temporal scale processes. Therefore, recent research using this technology provided new insights in zooplankton ecology (Dinning and Metaxas 2012, Sato et al. 2013), phytoplankton production (Price and Pospelova 2011) and nitrogen cycle (Manning et al. 2010).

In 2006, a long-term multidisciplinary imaging module was developed at the Ifremer research center (Brest, France) to study community dynamics and patterns of succession in remote marine environments (Sarrazin et al. 2007). The TEMPO-mini module, designed to be connected on a deep-sea network, was tested in the fall 2008 on the VENUS cabled network before its long-term deployment on the Juan de Fuca ridge (Auffret et al. 2010). This permitted the acquisition of live environmental and video data from the seafloor at $97 \mathrm{~m}$ in Patricia Bay, Saanich Inlet, located off Sidney, BC (Canada). We took advantage of this 5-month test deployment to examine the factors that influence benthic assemblage dynamics at small temporal scales in the oxygen fluctuation zone of this deep fjord. More specifically, we aimed at (i) quantify the role of measured environmental conditions (oxygen concentrations, temperature, salinity and turbidity) on species composition; (ii) assess the role of biotic interactions on the distribution and behaviour of different visible megafaunal species; and (iii) examine activity rhythms of species inhabiting the fjord and their potential corresponding to known tidal signals. This data allowed a comparison with similar previous studies conducted in the same area under more severe hypoxic conditions (Matabos et al. 2011, 2012) 


\section{MATERIAL AND METHODS}

\section{Tempo-mini and image acquisition}

TEMPO-mini is a custom-designed instrument package created through a collaboration between Ifremer's scientists and engineers for real-time monitoring of deep-sea benthic communities and their habitats (Auffret et al. 2010). The TEMPO-mini ecological module is built around a compact polyethylene structure assembled by titanium rods and bolts to save weight and prevent corrosion during long-term deployments. TEMPO-mini uses a 2 megapixel high resolution Axis $223 \mathrm{M}$ network camera integrated in a titanium housing, along with $4 \times 20 \mathrm{~W}$ LED projectors. The package is also equipped with an Aanderaa optode for in situ oxygen measurements, and a temperature probe.

TEMPO-mini was deployed on a NEPTUNE Canada junction box at $97 \mathrm{~m}$ depth in Saanich Inlet using the ship crane (Figure 1). On the bottom, the Remotely Operated Vehicle (ROV) ROPOS connected the module to the VENUS network using its mechanical arm. The deployment occurred late September 2008 and the recovery early February 2009. The camera was located at $60.5 \mathrm{~cm}$ above the bottom, in a $45^{\circ}$ angle (Figure 2) and acquired 3 minutes of video every half hour between October 28th 2008 and February 2nd 2009. However, due to technical issues, no video imagery was acquired from September 28 to October 29, 2008, generating a big gap at the beginning of the time-series. In addition, loss of power in LEDs and biofouling issues resulted in poor visibility, and video images acquired in January and February 2009 were not usable. As a result, the sequences analysed only covered a 2 month period, between October $30^{\text {th }}$ and December $31^{\text {st }} 2008$.

\section{Biological data extraction from video imagery}

Using known in situ measurements and the angle of the camera, we applied a perspective grid to assess the surface area of the field of view (Figures 2 and 3). Since the image background had limited visibility, the grid was used to delineate a smaller area in which the 
biological data were extracted in order to maintain consistency among images and limit errors. Due to the huge amount of images generated, analyses include only one clip per hour, totalizing 24 clips of 3 minutes per day (half of the images). This subsampling provided enough high frequency data acquisition to detect a potential semidiurnal rhythm. Animals were identified to the lowest possible taxonomy level and counted using Image $\mathrm{J} 1.44$ open source software (Rasband, 2012).

Every hour, qualitative and semi-quantitative information were extracted from video clips (Table 1). Organisms were analysed using two strategies depending on their mobility: mobile species were characterized by density variations whereas the activity rhythm of sessile species was recorded. It included length variations of anemone stalks (Figure 3) and tentacle orientation, zooplankton density index and species presence/absence. The abundance of organisms was extracted at the $30^{\text {th }}$ second of the clip, 25 seconds after the lighting starts in order to minimise its influence on the observations (Table 1). Individuals of each species observed in the studied area were counted and species abundance data were converted to densities of individuals per $\mathrm{m}^{2}$ by dividing the total number of individuals by the total surface area of $1.02 \mathrm{~m}^{2}$. The nutritional behaviour of the anomurid squat lobster Munida quadrispina and species interactions were also reported. All other relevant information regarding to behaviour or visible environmental conditions was also documented (Table 1). The full data set analysed included 1381 video sequences totalizing 69 hours and 30 minutes of imagery.

\section{Environmental conditions}

All environmental variables, i.e. dissolved oxygen concentrations, temperature, salinity and turbidity, were obtained from the VENUS Instrument Platform (VIP). The VIP was located at 97.4 $\mathrm{m}$ depth and $75 \mathrm{~m}$ from TEMPO-mini (Figure 1).We therefore considered that the conditions recorded at the VIP were representative of those experienced by the fauna observed by the Tempo-mini module. For comparisons between environmental variables and observed changes 
in megafaunal species, we computed the hourly average of each environmental variable using data measured half an hour before and half an hour after the biological observations, to account for the distance between the camera and sensors.

\section{Uni- and bivariate analysis}

Species association - In order to detect possible association among species, the kendall tau rank correlation coefficient was computed for each pair of species using the cor.test function in R.

Identification of significant periodicities -Periodicities in environmental data, species activity and behaviour were screened using periodograms. A Whittaker-Robinson periodogram was used to screen periodicities in quantitative data, i.e. species densities and environmental parameters, and their statistical significances was tested by a permutation procedure (Legendre and Legendre 2012). For the qualitative data, such as anemone lengths, tentacle orientation, nutrition modes and biotic interactions, the contingency periodogram was selected (Legendre et al. 1981) . This type of periodogram is based on a Buys-Ballot contingency table where each row is the state (i.e. index value or $0 / 1$ for presence-absence data) of the variable while in the columns is reported the number of times an observation occurs in a given period (Legendre et al. 1981).

\section{Multivariate analyses}

In analysis of community ecology, while Euclidean distance is inappropriate for ordination of species abundance data with many zeros, the Hellinger distance is a measure recommended for this type of data (Legendre and Legendre 2012). A Hellinger transformation was thus applied to species density data prior to multivariate analyses. The transformation consists in taking the square root of the relative abundance of each species at a given observation date. After this 
transformation, analysis based on Euclidean distance like canonical redundancy analysis (RDA) preserve the Hellinger distance among sites (Legendre and Gallagher 2001). The RDA, used to assess the relation between species and environmental data, combines aspects of ordination and regression and uses a permutation procedure to test the significance of the explained variation (Legendre and Legendre 2012). All multivariate analyses were performed on normalized (i.e. centred and scaled) environmental data. Calculations were performed through $\mathrm{R}$ language functions (R Core Development Team 2013).

Identification of temporal breaks - First, putative temporal breaks were identified using a multivariate regression tree (MRT) (De'ath 2002) computed on two different datasets: (1) the species density data, (2) and the environmental data matrix. This method defines groups of dates that are similar in faunal composition/environmental conditions while temporally adjacent. The MRT is a partitioning method of the multivariate response data table (i.e. species density data or environmental matrix) constrained along the axis of a single explanatory variable, here the time, to generate temporal consistent groups of observations. The tree structure is generated by successively partitioning the whole dataset into mutually exclusive groups, and each split is chosen to maximize the $\mathrm{R}^{2}$ (or among sum-of-squares). The tree with the lowest cross-validation error is chosen as the best predictive tree. At the end of the procedure, each leaf of the tree is characterized by the number of observations and the value of the explanatory or constraining variable (here time) defining each split (or node). The tree was computed using the mvpart" library (De'ath 2002) in the R statistical language.

Species assemblages temporal variability and influence of the environment- Prior to analysis, multispecies data was checked for a linear trend and temporal structure of the faunal assemblagewas investigated on residual data after detrending species density data. Data was detrended using a RDA and all axes were kept (full model used). The temporal distribution of 
species densities was then quantitatively described using distance-based Moran's Eigenvectors Maps (dbMEMs; Borcard and Legendre 2002; Peres-Neto and Legendre 2010) on quantitative data only. This method, more commonly used in spatial analysis of ecological studies, has been successfully applied to time-series data for the detection and quantification of temporal variability over a wide range of scales detectable by the sampling design (Angeler et al. 2009; Legendre and Gauthier, 2014). We applied this technique to our time series to identify temporal variability in species composition and densities of the studied assemblage. In this case, the method used time coordinates of the sampling dates to build a matrix of Euclidean distances among observation dates. This matrix was then truncated at a user defined threshold to only retain the distance between neighbouring dates. In order to detect features smaller than the widest gap (54 hours), three observation dates were added to the time data vector, leaving a gap of 19 hours, used as our truncation value (Borcard et al. 2004). A principal coordinate analysis (PCoA) on the truncated distance matrix was computed and only the positive dbMEMs variables were kept. Negative PCNMs describe negative correlations between neighbouring observations, in our case two consecutive hours and are thus hard to relate to known natural processes or variability. After the PCoA, the supplementary observation dates were removed from the dbMEMs matrix. This generates a loss of orthogonality among the principal coordinates but the effect is negligible if the number of added objects is small - in our case 3 out of 1381 observations (Borcard et al. 2004). The resulting principal coordinates (dbMEMs eigenfunctions) were irregular sinusoids describing all the temporal scales that could be observed in the sampling design. The dbMEMs variables were generated using the PCNM function implemented in the $\underline{\underline{P}} \mathrm{CNM}^{\prime}$ package $(\mathrm{R}$ development Core Team 2013). Those dbMEMs variables were then used in a canonical redundancy analysis (RDA), implemented in the vegan' package ( $R$ Development Core Team 2013), to explain the variation in faunal assemblage structure (response variables) among observation dates. 
Significant dbMEMs functions were identified by a forward selection procedure (Dray et al. 2006) implemented in the packfor‘ package (R development Core Team 2013). This procedure uses the results of a permutation test (999 random permutations) to test the significance of the explanatory variables (dbMEMs functions) successively entering the model and stops when either the p-value of a newly included variable is higher than an alpha threshold of 0.05 , or the contribution (adjusted $\mathrm{R}^{2}$ ) of newly included variable is lower than a threshold equal to the adjusted $R^{2}$ value from the initial RDA. The significant dbMEMs functions were then plotted and grouped into sub-models. The threshold for sub-models was defined according to known environmental signals (e.g. tides) and processes, or when MEMs become non-significant creating a large gap between groups of significant ones. Different thresholds were used to test for the robustness of our choice and results remained unchanged. RDAs were used to test the significance of each sub-model (i.e. time scale) on the biological matrix, followed by canonical analyses of variance (ANOVAs) to test the significance of each RDA axis. The temporal submodels obtained were submitted to RDAs with environmental data to determine the explanatory variables related to the species density data at each scale.

Relationships between zooplankton relative abundance, anemones' orientation and stalk's length, squat lobster behaviour and environmental parameters were also investigated using canonical redundancy analyses (RDA) as described above.

\section{RESULTS}

\section{Environmental characterization}

Dissolved oxygen (DO) concentration was low at the beginning of the study period between October 28 and November 7, ranging between 0.12 and $0.70 \mathrm{ml} / \mathrm{l}$. A first intrusion of DO was recorded on November 8, 2008, with oxygen concentrations reaching $1.53 \mathrm{ml} / \mathrm{l}$ on November 12, 2008 (Figure 4). A second, more important intrusion of DO occurred on December $28^{\text {th }}$ probably when a mass of cold, fresher water entering the mouth of Saanich Inlet 
replaced the warmer, saltier, oxygen-depleted water (Figure 4) with hourly average DO concentrations reaching $2.3 \mathrm{ml} / \mathrm{l}$ on December $31^{\text {th }}, 2008$. These oxygen intrusions were not accompanied by changes in density. DO concentrations were highly variable at hourly scales, especially during the intrusion events. Temperature and salinity varied little at the beginning of the study period with values around $9.26^{\circ} \mathrm{C}\left( \pm 0.02{ }^{\circ} \mathrm{C}\right)$ and $31.12 \mathrm{PSU}( \pm 0.05 \mathrm{PSU})$ respectively. During the December $30^{\text {th }}$ intrusion event, temperature reached a minimum of $8.34^{\circ} \mathrm{C}$ the next day and displayed a high hourly variability.

Transmission data translate the amount of turbidity in the study area, with $100 \%$ for no turbidity and $0 \%$ when there is no light transmission, representing high turbidity. Values varied between $45.7 \%$ and $70.9 \%$ over the study period, with a mean value of $64.6 \%$. The 15 and 16 of December were characterized by the highest turbidity levels (Figure 4).

Tides on this coast are mixed-semidiurnal with spring-neap amplitude variations (Mofjeld et al. 1995). Periodograms performed on the raw hourly average data only detected periodicities from 15 to 17 days in dissolved oxygen data $(p<0.05)$. After detrending the data, periodograms highlighted a 15/17 days fortnightly periodicity for both DO concentrations and transmission rate, and, for salinity, periodicities of 24 hours - in relation to the solar or lunar diurnal cycle - and 4/5, 8/9, 11, 13 and 16 days (Figure 5).

\section{Species distribution patterns}

Eight taxonomic groups (from species to family) and 8376 individuals were counted over the entire period. The main mobile species encountered were the anomurid squat lobster Munida quadrispina and pleuronectid flatfish mainly represented by the slender sole Lyopsetta exilis (other flatfish occasionally present were the Pacific dover sole Microstomus pacificus, and the English sole Parophrys vetulus). Other fish species were occasionally present in the field of view including the bluebarred prickleback Plectobranchus evides, the blacktip poacher Xeneretmus latifrons, a zoarcidae eelpout and a toadfish species. Sessile taxa were represented 
by Suberitidae sponges and Metridium farcimen anemones. An unidentified nudibranch species, comb jellies/ctenophores and the hyppolytidae shrimp Spirontocaris sica were also occasionally seen. All species displayed high daily fluctuations in abundances (Figure 6). The squat lobster Munida quadrispina was the most abundant species, with raw densities varying from 0 to 16 ind. $/ \mathrm{m}^{2}$ throughout the 2-month period, and occurred in higher number during December. Flatfish density was higher early November at the beginning of the observation period. Other species usually displayed low abundances ( $<2$ ind./m²; Figure 6). Few individuals of toadfish were observed between November $24^{\text {th }}$ and $29^{\text {th }}$.

Species associations are presented in Table 2. Densities of the squat lobster $M$. quadrispina were significantly negatively correlated with those of the flatfish, blacktip poacher and toadfish, and positively correlated with those of the zoarcidae eelpout and bluebarred prickleback (Kendall tau correlation coefficients, $\mathrm{p}<0.05$ ). Negative relationships were also detected between flatfish densities and, those of the shrimp, eelpouts and toadfish; and between toadfish densities and, those of eelpouts and shrimp. Significant positive relationships were observed between densities of the toadfish and poachers, as well as between those of eelpouts and shrimp.

\section{Activity Rhythms}

A wide range of rhythmicity characterized the different species observed in this study. Only squat lobsters showed no significant periodicity (results not shown). Flatfish exhibited a periodicity at 6 days and 14.5 days corresponding to the fortnightly spring/neap tide lunar cycle (Figure 7). The eelpout displayed the same pattern with a periodicity at 1.5 days and ca. 12 days. The toadfish had only one significant periodicity at 19 days. The periodogram performed on the prickleback revealed a 12 hours periodicity and the corresponding harmonics in relation to the semi-diurnal tidal lunar cycle, as well as a significant rhythmicity at ca. $10,13,15$ and 16 days. Finally the periodograms performed on poachers and shrimp were similar (Figure 7: 
poachers) with a periodicity detected at 2.5 days and its harmonics at ca. $5,10,12$ and 17.5 days. Poachers displayed an additional fortnightly periodicity of 15 days.

The orientation of the anemones' tentacles did not display any periodicity, and no rhythm was detected in the $M$. quadrispina nutrition or biotic interactions. On the other hand, a ca. 4 and 8 day periodicities were highlighted in the stalk lengths of the two anemones (Figure 7).

\section{Species assemblage dynamics: relationships between biological data and environment}

The multivariate regression tree computed on environmental variables accounted for $55 \%$ of the total variance (Figure $8 \mathrm{~A}$ ). The first split explained $18.2 \%$ of the variance and separated observations made prior' and $\underline{\underline{a}}$ fter ${ }^{\prime}$ the second big oxygen intrusion event recorded on December $28^{\text {th }}$. Prior to that date, the second split correspond to the first oxygen intrusion event on November $11^{\text {th }}$. The tree computed on species densities along the temporal axis explained $23.5 \%$ of the total variance in species data and highlighted 4 main groups (Figure 8B). The first split $(21.6 \%$ of the variance) separated observations made $\underline{\underline{b}}$ efore' and $\underline{\underline{a f t e r}}$ November $24^{\text {th }}$ at $11: 30$. The secondary splits only explained $1.9 \%$ of the variance and separated observations made $\underline{\underline{\underline{b}}}$ efore' and $\underline{\underline{\text { after }}}$ November $16^{\text {th }}$ at 7:30 on one side and December $4^{\text {th }}$ at $9: 30$ on the other side. Observations made between November $24^{\text {th }}$ and December $4^{\text {th }}$ were characterized by the presence of toadfish.

The set of environmental variables considered in this study only accounted for $7.71 \%$ of the total variance in species density data. Even if a low proportion of variance is represented, the two first axis of the RDA were significant at 0.05 . The first axis of the redundancy analysis explained $6.05 \%$ of the total variance and is strongly related with DO concentrations and light transmission (Figure 9). The second axis explained $1.49 \%$ of the variance and was strongly driven by salinity and transmission. In terms of species, toadfish contributed the most to the first axis, related to higher DO concentrations while flatfish and squat lobsters contributed the most to 
the second axis. A linear trend explaining $2.5 \%$ of the total variance in species density data was detected.

The dbMEM analysis lead to the identification of four scales of variation in the structure of the benthic assemblage over the 2-month period: (i) broad (14.5 days), (ii) medium (4-6 days), (iii) small (2-3 days) and (iv) fine (ca. 24 hours) (Table 3). The broad scale, corresponding to the lunar fortnightly cycle, accounted for $19.5 \%$ of the total variance in the species density data and was significantly related with all four water properties, with a higher correlation with DO concentrations. Medium scale accounted for $8.7 \%$ of the total variance and was significantly related to all variables but light transmission. Salinity contributed the most to that sub-model. The small scale accounted for $5.7 \%$ of the total variance and was also significantly related to all variables but salinity. However, the contributions of the different water properties to this submodel were small. Finally, the fine scale accounted for only $2.4 \%$ of the total variance and was not related to any of the environmental variables considered in this study. The 24 hours cycle can be assimilated to the day/night diel cycle or the lunar diurnal tide.

\section{DISCUSSION}

Image acquisition with the ecological module Tempo-mini delivered high-resolution timeseries in the Saanich Inlet fjord (British Columbia, Canada) with hourly information on faunal assemblage dynamics, including changes in species composition and species behavior. One limitation in this study lays in the potential influence of the physical structure (Tempo-mini module) and the artificial lighting on species behavior. The influence of lights on invertebrates is unknown but this issue has recently been raised with the development of observatories and the use of camera systems to study benthic faunal communities (Matabos et al. 2011, 2012). While a study in the North Pacific showed no influence of the infrastructure on megafaunal abundances (Vardaro et al. 2007), it is recognized that light can modify the behavior of certain 
fish species (Krieger 1997; Widder et al. 2005; Doya et al. 2013, pers. observations). Here, the structure and lights were constant over the entire study period and we are confident that the changes we observed were mostly linked to external factors (Matabos et al. 2011, 2012). Finally, the small field of view $\left(1.02 \mathrm{~m}^{2}\right)$ coupled with low species abundance might limit our ability to detect activity patterns in mobile species like fish, and their extrapolations to larger scales should therefore be considered cautiously.

Physiography, hydrography, including deep-water renewal, and weather are the most important factors shaping fjord ecosystems habitats (Nordberg et al. 2001), and consequently strongly influence the benthic community structure (Renaud et al. 2007, Blanchard et al. 2010, Brewin et al. 2011). Limited circulation and isolation of deep basins in silled glacial fjords limit nutrient exchanges and larval dispersal (Renaud et al. 2007). In addition, carbon fluxes are generally low, resulting in low faunal abundances and biomasses (Blanchard et al. 2010). Hence, water stratification, by controlling productivity and anoxia, would play a major role in shaping fjord benthic communities (Timothy and Soon 2001, Blanchard et al. 2010, Brewin et al. 2011). In contrast, Saanich Inlet is one of the most productive fjords in the northern hemisphere (Grundle et al. 2009), hence food is not a limitation for its benthic communities. In response to this high productivity, hypoxia develops during summer and fall (Timothy and Soon 2001) and the fauna, adapted to those low oxygen conditions, can survive for short periods of anoxia (Tunnicliffe 1981; Matabos et al. 2012). Our results confirmed the role of oxygen on species assemblage dynamics in Saanich Inlet, but also highlighted and confirmed the significant role of lunar related fortnightly neap/spring tide forcing, and in a lesser extent the semi- diurnal tidal signal, on environmental conditions, fish activity and consequently species assemblage dynamics. Even though tides play an important role in fjord's hydrography (Gargett 2003), chronobiology studies in other fjords are not yet available in the literature. 


\section{Environmental variations}

Throughout almost the entire study period, dissolved oxygen concentrations were typical of hypoxic conditions (i.e. $1.4 \mathrm{ml} / \mathrm{l}$; Rabalais et al. 2010) and only reached oxic levels at the end of December. Those conditions are typical of a normal year in Saanich Inlet where, during the boreal fall, dense cold and oxygenated water enters over the inlet sill replacing deep anoxic water (Anderson and Devol 1973, Gargett 2003). The origin of the water mass entering over the inlet sill is a result of a complex interaction occurring in the neighboring Strait of Georgia, where deep dense water originating from the continental shelf and entering through the Juan de Fuca Strait mixes with the cold freshwater from the Fraser river discharge (Masson 2002). Those intrusion events occur as pulses linked with tidal forcing. Following a deep intrusion, two neap tides are necessary for the water to reach a density high enough to trigger a new flushing event (Masson 2002). The occurrence of two different intrusion events, varying in intensity, observed in this study probably result from this pulse mechanism. The second event had a stronger signature with a visible decrease in temperature and salinity. However, while deep-water renewals are known to be density-driven, the oxygen intrusions we observed were not accompanied by significant changes in density (Figure 4). Indeed, at the VENUS node sensor, oxygen changes appear to represent a bad proxy for deep renewal timing as some renewals result in DO increase while others are characterized by DO decreases if less oxygenated water from the depth is pushed upwards during the event (Manning et al. 2010). Therefore, water flowing in front of the sensor is of different nature than the non-mixed' dense oxygenated water entering the sill.

Light transmission values are a proxy of water visibility and therefore of the concentration of particles in the water. The visibility tended to decrease over the study period along with salinity. High turbidity levels started November 27, going up until December 6, which correspond to a visible decrease in transmission values, and what appeared to be higher current flows 
around December 16 when the peak in turbidity was recorded. These changes in environmental conditions were likely related to replacement of water masses following the pulses described above rather than pure mixing processes. The Whittaker-Robinson periodograms did not detect any significant periodicities in environmental variables except from 15 to17 days for the oxygen, corresponding to the fortnightly tidal signal. The observed strong punctual pulses/events probably masked more regular cycles in relation to known tidal (i.e. diurnal and fortnightly) periodicities. Indeed, when computing the periodograms on detrended data, the $15 / 17$ days periodicity was also detected in salinity and transmission rate. These variations, close to the lunar fortnightly cycle, could be explained by the role of spring tide mixing in nutrient renewal that generates fortnightly phytoplankton blooms and strongly affects biogeochemical processes (Gargett 2003, Grundle and Juniper 2011). In addition, salinity showed variations at lower periods from diurnal lunar tide signal of 24 hours to 12.8 days.

\section{Biological rhythms}

Behavioural rhythms result from the entrainment (modulation) of animals' physiology by predictable environmental fluctuations (Saunders 2002; Dunlap et al. 2004). While data on rhythmic behavior for marine species inhabiting aphotic zones are scant, an emerging literature on biological rhythms in deep areas devoid of light suggest the importance of tide- and lunarrelated rhythms in species activity (review in Aguzzi et al. 2011; Matabos et al. 2013; Doya et al. 2013, Cuvelier et al. in press) and reproduction (Mercier et al. 2011).

In this study, activity rhythms were highly variable among species. The two Metridium farcimen anemones, visible in our images, showed $4 / 5$ days and 8 days periodicities in their stalk lengths. Those values do not correspond to any known environmental signal but the presence of significant harmonics in the periodogram analyses suggests that they were not an artefact. The observation of more individuals will help better characterize and explain the rhythm observed. The detected signal might reflect a physiological endogenous rhythm linked to a 
nutritional process. Nevertheless, the rhythm observed could not be related to periodicity in zooplankton, the principal prey of M. farcimen (Sebens and Koehl 1984). Zooplankton densities were only evaluated visually with a semi-quantitative index, and temporal variations patterns in zooplankton densities from in situ sampling could have led to different results. A study conducted over 2 years at the same location described the zooplankton vertical daily migration variability using quantitative acoustic data and highlighted the influence of life history traits and environmental cues in migration timing (Sato et al. 2013). The authors assumed that the migrating layer was mainly composed of euphausids. In our study, the zooplankton was composed of euphausids and copepods in proportions highly variable from day to day but no diurnal pattern related to dial vertical migration (dvm) was observed. This suggests that the TEMPO-mini camera does not constitute a good tool for estimating zooplankton migration patterns at depth.

Four different patterns in activity rhythms were highlighted in mobile species. The flatfish displayed a 6 day periodicity that did not coincide to any known cyclic signal, and a lunar related fortnightly cycle at 14.5 days in relation to spring/neap tide forcing. Similarly, Matabos et al. (2012) detected a fortnightly cycle (15 days) at $104 \mathrm{~m}$ depth in a benthic assemblage of Saanich Inlet. During spring tide, increased tidal mixing outside of the fjord create a pressure gradient with a seaward flow of surface water and an inward flow of nutrient-rich sub-surface waters (Gargett 2003). Therefore, this nutrient injection in Saanich Inlet appears to support a fortnightly cycle of phytoplankton blooms. Matabos et al. (2012) hypothesized that the community responded to this tidal forcing through changes in abundance and activity of zooplankton, which will mostly influence the planktivorous Lyopsetta exilis (Pearcy and Hancock 1978). Although the flatfish' reported in this study is represented by different species, L. exilis appeared to be the most dominant over the study period (pers. obs.). Interestingly, the only species displaying the fortnight cycle were highly mobile fish which are more likely to promptly react to change in food quality/availability. Several fish species, including the prickleback Plectobranchus evides and the 
pelagic fish (results not shown), displayed a semi-diurnal cycle and a diel cycle. Since smallscale significant periodicities had 12-hour harmonics, the observed pattern is more likely to be tidally-driven rather than related to the day/night cycle. Indeed, a 12-hours rhythmicity along with the corresponding harmonics suggest an influence of internal tidal waves which are known to affect mixing processes and consequently physico-chemical conditions of deep basins ' waters in fjords (Inall and Rippeth 2002; Garrett 2003). Similarly, Wagner et al. (2007) showed the occurrence of an endogenous clock in deep-sea fishes in relation with internal waves affecting water flow variations. However, we were not able to determine if the observed signal was linked to endogenous or exogenous rhythms in response to change in habitat condition. The shrimp and poacher Xeneretmus latifrons exhibited similar periodicities in their abundances with a 2.5 days and harmonics at 5 and 9/10 days and a common periodicity at $\sim 17$ days. The 17-day period coincided with the periodicity detected in dissolved oxygen concentration and might explain the behavioral response observed in these two taxa. Finally, the squat lobster Munida quadrispina did not display any rhythmicity supporting previous observations in the same area (Matabos et al. 2011).

\section{Species assemblage structure and environmental influence}

Temporal variations in the epibenthic megafaunal community were assessed using species densities. Over the 2 months, changes in environmental conditions only explained $7.7 \%$ of variation in the structure of the observed assemblage while a regression performed along the time explained $23.5 \%$ of that same variation. The multivariate regression tree compiled on density data showed that the first split on November 24 explained $21.6 \%$ of the variance. The most notable differences at this date mainly involved changes in the composition of the benthic fish assemblage. Prior to November 24, this assemblage was dominated by the flatfish, while after there was an increase in benthic fish diversity with the arrival of toadfish and poachers. This change occurred 12 days after the first intrusion of dissolved oxygen in the area. In Saanich 
Inlet, except for the flatfish Lyopsetta exilis, benthic fish are known to be less tolerant to severe hypoxic conditions, migrating deeper in the basin only when conditions become milder (Matabos et al. 2012). In this study, the prickleback Plectobranchus evides was present during the twomonth period. On the contrary, Matabos et al. (2012) reported that during severe hypoxic conditions in another area of the fjord, only the highly tolerant Lyopsetta exilis, Munida quadrispina and shrimp Spirontocaris sica were observed. One main difference was the presence of sulfo-oxydizing bacteria Beggatioa spp. at the Matabos et al. (2012) site. These bacteria develop at the oxic-anoxic interface where they oxidize reduced sulfides with molecular oxygen (Jørgensen and Revsbech 1983a); they are known to rapidly migrate upwards, following variations in oxygen concentrations in the sediments (Jørgensen and Revsbech 1983b). Their presence is thus a proxy of diffusing sulfides from the subsurface anoxic sediment (Matabos et al. 2012). In this study, no bacterial mat developed, suggesting that the surface sediment did not reach anoxic conditions at the end of the summer. This probably explains the highest taxonomic diversity observed. The second break on December 4 coincided with an increase in $X$. latifrons and $M$. quadrispina densities, and more occurrences of the zoarcidae eelpout. These changes were associated with a slight decrease in dissolved oxygen concentration until the next strong intrusion event on December 28. Our results support the presence of an increased taxonomic diversity at times where environmental conditions (mostly oxygen) become accessible for less tolerant species.

The measured environmental variables explained $6.4 \%$ of the variance in species data, while again, temporal variables (i.e. MEMs) accounted for a much higher proportion. Four temporal submodels (i-iv) were defined from all significant MEMs to represent the temporal structure of the epibenthic assemblage. The most important temporal component detected was (i) the lunar fortnightly pattern, which was highly correlated with DO and in a lesser extent, temperature. This pattern coincides with periodogram results obtained for both environmental 
conditions and fish activity confirming the significant role of the lunar fortnightly cycle. Those results support and reinforce observations presented by Matabos et al. (2012) who suggested that the benthic communities responded to the neap/spring tidal forcing through changes in physico-chemical parameters (mainly oxygen) and the abundance and activity of zooplankton that feed on the enhanced phytoplankton production (see above; Gargett 2003).

The (ii) medium (5-6 days) and (iii) small (2-3 days) scales defined in the temporal model of the epibenthic assemblage were also significantly correlated with environmental variables but those correlations were weak. The medium scale coincided with periodicities detected in salinity variations, which is the variable explaining most of the variance at that scale (Table 3 ), while the small scale coincided with the shrimp and $X$. latifrons activity. The link with salinity does not necessarily imply that there is a direct causal link to species activity, but the same underlying process may have generated this common periodicity. While our study period only covered 2 months, it detected variations in faunal assemblage structure at the same scales as the one identified in a full year study done at the same location (Matabos et al. 2012) suggesting that our results are not specific to the boreal fall/winter season. A third oxygen intrusion occurred in March 2009 leading to DO values ranging from 3 to $4 \mathrm{ml} / \mathrm{l}$ in spring and summer (VENUS data http://venus.uvic.ca/data/data-archive/). While scales of variations would probably remain unchanged, we expect to find a higher species diversity in the summer months when oxygen concentrations are higher (VENUS data, Matabos et al. 2012), diversity that would in turn affect biotic interactions within the community.

Most of the variance, including patterns detected at smaller scales, was not explained by the available environmental variables suggesting that other parameters might play an important role in benthic community dynamics in Saanich Inlet. Knowing the low current values in the area (averaging less than $5 \mathrm{~cm} / \mathrm{s}$; Yahel et al. 2008), it is unlikely that current variations explain the biological patterns observed. On the other hand, biotic interactions like competition for food or 
predation, or species life-history traits might explain part of the unexplained variation (Borcard et al. 2004). The finest scale (iv) of the temporal model revealed the importance of the tidal cycle ( 24 hours) which probably reflects the role of species activity rhythms on assemblage dynamics. However, in this analysis we only considered fluctuations in species abundances (Aguzzi et al. 2012). Direct ethological observations could be useful to detect the origin of the observed rhythms and to understand the behavioral mechanism underlying the fluctuations observed. One solution would be to study the benthic species individually under constant conditions to reveal intrinsic mechanism (endogenous) underlying the functioning of their biological clock (Johnson et al. 2003, Chiesa et al. 2010). In addition, the full analysis of our entire video dataset over a month could bring more insights on the mechanisms associated with tidal related rhythms. However, the amount of time and human resources needed to process such an amount of data is enormous, emphasizing the need for automated video processing (reviewed in Aguzzi et al. 2012).

\section{Conclusions}

Video observation systems deployed on the seafloor provide access to information not available before and represent great tools to detect and describe biological rhythms at depths (Aguzzi et al. 2012; Doya et al. 2013, Sarrazin et al. in press, Cuvelier et al. in press) which are essential to understand ecosystem functioning and dynamics (Marques and Waterhouse 2004; Morgan 2004). While observations in the lab can bring important insights into the biology of individual species, they cannot supplement observations in the field where the complexity of the ecosystem is influenced by species interactions and the unpredictability of the environment (Marques and Waterhouse 2004; Nevill et al. 2004). Thus, activity rhythms of animals can be masked by factors like food availability (Fernandéz de Miguel and Aréchiga 1994), changes in water masses (Matabos et al. 2013) and dissolved oxygen concentrations (Schurmann et al. 1998; Matabos et al. 2011). The need to statistically separate the effect of meteorological factors 
and activity rhythms was recognized by Nevill et al. (2004). His method allows one to determine how species activity co-vary with changing environmental conditions but is not applicable at the system level when dealing with a multispecies assemblage in order to understand ecosystem dynamics as whole. In this study the combination of in situ approach to observe species behaviour and activity, combined to novel statistical approach like the distance-based Moran Eingenvectors Maps (MEM) analysis which handles autocorrelation and temporal correlation, demonstrated the ability of observatories to describe how species vary with changes in environmental conditions at the multispecies level.

At larger scales, the main advantage of seafloor observatories lays in the ability to conduct long-term survey and simultaneously measurements of multiple variables at a single point. One interesting application is thus the detection of extreme events and monitoring of the response of benthic communities (Gaines and Denny 1993). For example, benthic activity rhythms in a submarine canyon were only detected when considering short time segments corresponding to periods before and after storm events (Matabos et al. 2013). To date, there is no standardized way of defining an event as their characterization is obviously dependent of the type of habitats. Observatories represent new avenues to conduct science in the world's oceans. They are just starting to provide preliminary direction and answers to determine thresholds of environmental and faunal changes in different types of marine habitats. Understanding natural changes of benthic communities is becoming urgent in an era where the oceans are rapidly changing and in which the resources they contain are increasingly sought after.

\section{Aknowledgements}

The authors would like to thank the Ifremer engineer team (Ifremer/REM/RDT) for its dedicated support in the design, maintenance and improvement of the TEMPO deep-sea modules over the years. We would also like to thank P. Rodier for this help with the construction of the perspective grid and drawing, J. Nephin for her help in video processing and J. Rose for his support in 
technical issues. We would also like to thank the VENUS and ROV ROPOS teams for their helpful collaboration on the field. Finally, we would like to thank two anonymous reviewers for their helpful comments on a previous version of the manuscript. This work was part of $M$. Matabos post-doctoral work funded by the Canadian Healthy Ocean Network.

\section{References}

Aguzzi, J., Bahamon, N., and Marotta, L. 2009. The influence of light availability and predatory behaviour of the decapod crustacean Nephrops norvegicus on the activity rhythms of continental margin prey decapods. Mar. Ecol. 30(3): 366-375.

Aguzzi, J., and Company, J.B. 2010. Chronobiology of deep-water decapod crustaceans on continental margins. Adv. Mar. Biol. 58: 155-225. Available from http://www.ncbi.nlm.nih.gov/pubmed/20959158.

Aguzzi, J., Company, J.B., Costa, C., Matabos, M., Azzurro, E., Manuel, A., Menesatti, P., Sarda, F., Canals, M., Delory, E., Cline, D.E., Favali, P., Juniper, S.K., Furushima, Y., Fujiwara, Y., Chiesa, J.J., Marotta, L., Bahamon, N., and Priede, I.G. 2012. Challenges to the assessment of benthic populations and biodiversity as a result of rhythmic behaviour: video solutions from cabled observatories. Oceanogr. Mar. Biol. 50: 233-284.

Aguzzi, J., Company, J.B., Costa, C., Menesatti, P., Garcia, J.A., Bahamon, N., Puig, P., and Sarda, F. 2011. Activity rhythms in the deep-sea: a chronobiological approach. Front. Biosci. 16: 131-150.

Anderson, J.J., and Devol, A.H. 1973. Deep water renewal in Saanich Inlet, an intermittently anoxic basin. Estuar. Coast. Mar. Sci. 1: 10. doi: 10.1016/0302-3524(73)90052-2.

Angeler, D.G., Viedma, O., and Moreno, J.M. 2009. Statistical performance and information content of time lag analysis and redundancy analysis in time series modeling. Ecology 90: 3245-3257. Available from http://www.ncbi.nlm.nih.gov/pubmed/19967879.

Auffret Y., Coail, J.-Y., Delauney, L., Legrand, J., Dupont, J., Dussud, L., Guyader, G., Ferrant, A., Barbot, S. Laes, A. (2009). Tempo-Mini: A Custom-designed instrument for real-time monitpring of hydrothermal vent ecosystems. Instru. Viewpoint. 8, 17.

Blanchard, A.L., Feder, H.M., and Hoberg, M.K. 2010. Temporal variability of benthic communities in an Alaskan glacial fjord, 1971-2007. Mar. Environ. Res. 69: 95-107. Available from http://dx.doi.org/10.1016/j.marenvres.2009.08.005.

Borcard, D., and Legendre, P. 2002. All-scale spatial analysis of ecological data by means of principal coordinates of neighbour matrices. Ecol. Modell. 153: 51-68. doi: 10.1016/S03043800(01)00501-4. 
Borcard, D., Legendre, P., Avois-Jacquet, C., and Tuomisto, H. 2004. Dissecting the spatial structure of ecological data at multiple scales . Ecology 85: 1826-1832. Eco Soc America. doi: $10.1890 / 03-3111$.

Brewin, P.E., Probert, P.K., and Barker, M.F. 2011. Relative influence of processes structuring fjord deep-water macrofaunal communities across multiple spatial scales. Mar. Ecol. Prog. Ser. 425: 175-191. doi: 10.3354/meps08994.

Burd, B.J., and Brinkhurst, R.O. 1984. The distribution of the galatheid crab Munida quadrispina (Benedict 1902) in relation to oxygen concentrations in British Columbia fjords. J. Exp. Mar. Bio. Ecol. 81: 1-20.

Chiesa, J.J., Aguzzi, J., Garcia, J.A., Sarda, F., De La Iglesia, H. 2010. Light intensitydetermines temporal niche switching of behvioural activity in deep water Nephrops novegicus (Crustacea: Decapoda). J. Biol. Rhythms 25: 277-287.

Cohen, Y. 1978. Consumption of Dissolved Nitrous-Oxide in an Anoxic Basin, Saanich Inlet, British-Columbia. Nature 272: 235-237.

Cuvelier, D., Legendre, P., Laes, A., Sarradin, P.-M., Sarrazin, J. Rhythms and community dynamics of a hydrothermal tubeworm assemblage at Main Endeavour Field - A multidisciplinarydeep-sea observatory study. PLoS ONE (in press)

De'ath, G. 2002. Multivariate Regression Trees: A New Technique for Modeling SpeciesEnvironment Relationships. Ecology 83: 1105-1117. doi: 10.2307/3071917.

Dinning, K.M., and Metaxas, A. 2012. Patterns in the abundance of hyperbenthic zooplankton and colonization of marine benthic invertebrates on the seafloor of Saanich Inlet, a seasonally hypoxic fjord. Mar. Ecol. 34(1): 2-13;

Doya, C., Aguzzi, J., Pardo, M., Matabos, M., Company, J.B., Costa, C., Mihaly, S., and Canals, M. 2013. Diel behavioral rhythms in sablefish (Anoplopoma fimbria) and other benthic species, as recorded by the Deep-sea cabled observatories in Barkley canyon (NEPTUNECanada). J. Mar. Syst. 130/69-78. Available from http://dx.doi.org/10.1016/j.jmarsys.2013.04.003 [accessed 24 April 2013].

Dray, S., Legendre, P., and Peresneto, P. 2006. Spatial modelling: a comprehensive framework for principal coordinate analysis of neighbour matrices (PCNM). Ecol. Modell. 196: 483493. doi: 10.1016/j.ecolmodel.2006.02.015.

Dunlap, J.C., Loros, J.J., and DeCursey, P. 2004. Chronobiology: Biological Timekeeping. Sinauer, Sunderland, Massachusets.

Fernandéz de Miguel, F., and Aréchiga, H. 1994. Circadian locomotor activity and its entrainment by food in the crayfish Procambarus clarkii. J. Exp. Biol. 190: 9-21.

Gaines, S., and Denny, M. 1993. The largest, smallest, highest, lowest, longest, and shortest: extremes in ecology. Ecology 74: 1677-1692. doi: 10.2307/1939926. 
Gargett, A. 2003. Physical processes associated with high primary production in Saanich Inlet, British Columbia. Estuar. Coast. Shelf Sci. 56: 1141-1156. doi: 10.1016/S02727714(02)00319-0.

Garrett, C. 2003. Internal Tides and Ocean Mixing. Science (80-. ). 301: 1858-1859. American Association for the Advancement of Science. doi: 10.1126/science.1090002.

Glover, A.G., Gooday, A.J., Bailey, D.M., Billett, D.S.M., Chevaldonné, P., Colaço, A., Copley, J., Cuvelier, D., Desbruyères, D., Kalogeropoulou, V., Klages, M., Lampadariou, N., Lejeusne, C., Mestre, N.C., Paterson, G.L.J., Perez, T., Ruhl, H., Sarrazin, J., Soltwedel, T., Soto, E.H., Thatje, S., Tselepides, A., Van Gaever, S., and Vanreusel, A.. 2010. Temporal change in deep-sea benthic ecosystems: a review of the evidence from recent time-series studies. Adv. Mar. Biol. 58: 1-95. doi: 10.1016/B978-0-12-381015-1.00001-0.

Grundle, D.S., Timothy, D.A., and Varela, D.E. 2009. Variations of phytoplankton productivity and biomass over an annual cycle in Saanich Inlet, a British Columbia fjord. Cont. Shelf Res. 29: 2257-2269. Elsevier. doi: 10.1016/j.csr.2009.08.013.

Grundle, D.S., Juniper, S.K. 2011. Nitrification from the lower euphotic zone to the sub-oxic waters of a highly productive British Columbia fjord. Marine Chemistry 123: 173-181.

Herlinveaux, R.H. 1962. Oceanography of Saanich Inlet in Vancouver Island British Columbia. J. Fish. Res. board Canada 19: 1-37.

Inall, M., and Rippeth, T.P. 2002. Dissipation of tidal energy and associated mixing in a wide fjord. Environ. fluid Mech. 2: 219-240.

Johnson, C.H., Elliott, J.A., and Foster, R. 2003. Entrainment of circadian programs. Chronobiol. Int. 20: 741-774. Available from http://eutils.ncbi.nlm.nih.gov/entrez/eutils/elink.fcgi?dbfrom=pubmed\&id=14535352\&retmod $\mathrm{e}=\mathrm{ref} \& \mathrm{cmd}=$ prlinks.

Jørgensen, B.B., and Revsbech, N.P. 1983a. Colorless Sulfur Bacteria, Beggiatoa spp. and Thiovulum spp., in $\mathrm{O}(2)$ and $\mathrm{H}(2) \mathrm{S}$ Microgradients. Appl. Environ. Microbiol. 45: 12611270. Available from http://aem.asm.org/cgi/content/abstract/45/4/1261.

Krieger, K.J. 1997. Sablefish, Anoplopoma fimbria, observed from a manned submersible. In Biology and Management of sablefish, Anoplopoma fimbria. Edited by M. Saunders and M. Wilkens. U.S. Dep. Commer., NOAA Technical Reports NMFS 130. pp. 39-43.

Legendre, L., Fréchette, M., and Legendre, P. 1981. The contingency periodogram: a method of identifying rhythms in series of nonmetric ecological data. J. Ecol. 69: 965-979. Available from http://www.bio.umontreal.ca/legendre/reprints/J Ecol 69, 1981.pdf.

Legendre, P., and Gallagher, E. 2001. Ecologically meaningful transformations for ordination of species data. Oecologia 129: 271-280. Springer. doi: 10.1007/s004420100716.

Legendre, P., and Legendre, L. 2012. Numerical ecology. Third edition. Elsevier, Amsterdam. 
1. Legendre, P., and Gauthier, O. 2014. Statistical methods for temporal and space-time analysis of community composition data. P. R. Soc. B 281(1778): 20132728.

Levin, S.A. 1992. "The problem of pattern and scale in ecology: the Robert H. Mac Arthur award lecture". Ecology 73(6): 1943-1967. doi: 10.2307/1941447.

Manning, C.C., Hamme, R.C., and Bourbonnais, A. 2010. Impact of deep-water renewal events on fixed nitrogen loss from seasonally-anoxic Saanich Inlet. Mar. Chem. 122: 1-10. doi: 10.1016/j.marchem.2010.08.002.

Marques, M.D., and Waterhouse, J. 2004. Rhythms and ecology - do chronobiologists still remember nature? Biol. Rhythm. Res. 35(1-2): 1-2.

Masson, D. 2002. Deep Water Renewal in the Strait of Georgia. Estuar. Coast. Shelf Sci. 54: 115-126. doi: 10.1006/ecss.2001.0833.

Matabos, M., Aguzzi, J., Robert, K., Costa, C., Menesatti, P., Company, J.B., and Juniper, S.K. 2011. Multi-parametric study of behavioural modulation in demersal decapods at the VENUS cabled observatory in Saanich Inlet, British Columbia, Canada. J. Exp. Mar. Bio. Ecol. 401: 89-96. doi: 10.1016/j.jembe.2011.02.041.

Matabos, M., Bui, A.O. V, Mihály, S., Aguzzi, J., Juniper, S.K., and Ajayamohan, R.S. 2013. High-frequency study of epibenthic megafaunal community dynamics in Barkley canyon: A multi-disciplinary approach using the NEPTUNE Canada network. J. Mar. Syst. 130:56-68. Available from http://dx.doi.org/10.1016/j.jmarsys.2013.05.002.

Matabos, M., Tunnicliffe, V., Juniper, S.K., and Dean, C. 2012. A year in hypoxia: epibenthic community responses to severe oxygen deficit at a subsea observatory in a coastal inlet. PLoS One 7. doi: 10.1371/journal.pone.0045626.

Mercier, A., Sun, Z., Baillon, S., and Hamel, J.-F. 2011. Lunar rhythms in the deep sea: evidence from the reproductive periodicity of several marine invertebrates. J. Biol. Rhythms 26: 8286.

Mofjeld, H. O., González, F. I., Eble, M. C., \& Newman, J. C. 1995. Ocean tides in the continental margin off the Pacific Northwest Shelf. J. Geo. Res. 100: 10789. doi:10.1029/95JC00687

Morgan, E. 2004. Ecological significance of biological clocks. Biol. Rhythm. Res. 35: 3-12.

Naylor, E. 2005. Chronobiology: implications for marine resource exploitation and management. Sci. Mar. 69(S1): 157-167.

Nevill, A.M., Teixera, L. V., Marques, M.D., and Waterhouse, J.M. 2004. Using covariance to unravel the effects of meteorological factors and daily and seasonal rhythms. Biol. Rhythm. Res. 35: 159-169.

Nordberg, K. 2001. Climate, hydrographic variations and marine benthic hypoxia in Koljö Fjord, Sweden. J. Sea Res. 46: 187-200. doi: 10.1016/S1385-1101(01)00084-3. 
Pearcy, W.G., and Hancock, D. 1978. Feeding habits of Dover sole, Microstomus pacificus; rex sole, Glyptocephalus zachirus; slender sole, Lyopsetta exilis; and Pacific sanddab, Citharichthys sordidus, in a region of diverse sediments and bathymetry off Oregon. Fish. Bull. 76: 641-651.

Peres-Neto, P. R., \& Legendre, P. (2010). Estimating and controlling for spatial structure in the study of ecological communities. Global Ecology and Biogeography, 19(2), 174-184.

Price, A.M., and Pospelova, V. 2011. High-resolution sediment trap study of organic-walled dinoflagellate cyst production and biogenic silica flux in Saanich Inlet (BC, Canada). Mar. Micropaleontol. 80: 18-43.

$\mathrm{R}$ Development Core Team 2008. R: A language and environment for statistical computing. $R$ Foundation for Statistical Computing, Vienna, Austria.

Rabalais, N.N., Díaz, R.J., Levin, L. a., Turner, R.E., Gilbert, D., and Zhang, J. 2010. Dynamics and distribution of natural and human-caused hypoxia. Biogeosciences 7: 585-619. doi: 10.5194/bg-7-585-2010.

Rasband WS (2012). ImageJ, U.S. National Institutes of Health, Bethesda, Maryland, USA, 1997-2012.

Renaud, P.E., Włodarska-Kowalczuk, M., Trannum, H., Holte, B., Węsławski, J.M., Cochrane, S., Dahle, S., and Gulliksen, B. 2007. Multidecadal stability of benthic community structure in a high-Arctic glacial fjord (van Mijenfjord, Spitsbergen). Mar. Ecol. 34(1): 2-13. doi: 10.1007/s00300-006-0183-9.

Sato, M., Dower, J., Dewey, R., and Kunze, E. 2013. Second-order seasonal variability in diel vertical migration timing of euphausiids in a coastal inlet. Mar. Ecol. Prog. Ser. 480: 39-56. doi: 10.3354/meps10215.

Sarrazin, J., Blandin, J., Delauney, L., Dentrecolas, S., Dorval, P., Dupont, J., Legrand, J., Leroux, D. Leon, P., Leveque J.-P., Rodier, P., Vuillemin, R., Sarradin, P.-M. 2007. TEMPO: a new ecological module for studying deep-sea community dynamics at hydrothermal vents. Oceans 2007 - Europe. 1-2: 649-652.

Sarrazin Jozée; Daphne Cuvelier; Loïc Peton, Master; Pierre Legendre; Pierre-Marie Sarradin. (2014). High-resolution dynamics of a deep-sea hydrothermal mussel assemblage monitored by the EMSO-Açores MoMAR observatory. Deep-Sea Research (in press).

Saunders, D.S. 2002. Insect clocks. Elsevier Publishers, Amsterdam.

Schurmann, H., Claireaux, G., and Chartois, H. 1998. Changes in vertical distribution of sea bass (Dicentrarchus labrax L.) during a hypoxic episode. Hydrobiologia 371-372: 207-213.

Sebens, K.P., and Koehl, M.A.R. 1984. Predation on zooplankton by the benthic anthozoans Alcyonium siderium (Alcyonacea) and Metridium senile (Actiniaria) in the New England subtidal. Mar. Biol. 81: 255-271. 
Timothy, D.A., and Soon, M.Y.S. 2001. Primary production and deep-water oxygen content of two British Columbian fjords. Mar. Chem. 73: 37-51. doi: 10.1016/S0304-4203(00)00071-2.

Tunnicliffe, V. 1981. High species diversity and abundance of the epibenthic community in an oxygen-deficient basin. Nature 294: 354-356.

Tunnicliffe, V., Dewey, R., and Smith, D. 2003. Research plans for a mid-depth cabled seafloor observatory in Western Canada. Oceanography 16: 53-59.

Vardaro, M.F., Parmley, D., and Smith Jr., K.L. 2007. A study of possible reef effects" caused by a long-term time-lapse camera in the deep North Pacific. Deep Sea Res. Part I Oceanogr. Res. Pap. 54: 1231-1240. doi: 10.1016/j.dsr.2007.05.004.

Wagner, H.-J., Kemp, K., Mattheus, U., and Priede, I.G. 2007. Rhythms at the bottom of the deep sea: cyclic current flow changes and melatonin patterns in two species of demersal fish. Deep Sea Res. Part I Oceanogr. Res. Pap. 54: 1944-1956.

Widder, E.A., Robison, B.H., Reisenbichler, K.R., and Haddock, S.H.D. 2005. Using red light for in situ observations of deep-sea fishes. Deep Sea Res. Part I Oceanogr. Res. Pap. 52: 2077-2085. doi: 10.1016/j.dsr.2005.06.007.

Yahel, G., Yahel, R., Katz, T., Lazar, B., Herut, B., and Tunnicliffe, V. 2008. Fish activity: a major mechanism for sediment resuspension and organic matter remineralization in coastal marine sediments. Mar. Ecol. Prog. Ser. 372: 195-209.. doi: 10.3354/meps07688. 
Fig. 1.Location of instruments on the VENUS cabled network in Saanich Inlet (British Columbia, Canada). (A) Map of Saanich Inlet (top) and its location on Vancouver Island along the west coast of Canada (bottom). (B) Location of instruments in Patricia Bay, Saanich Inlet. VIP, VENUS Instrument Platform; TM, TEMPO-mini; Camera, VENUS camera.
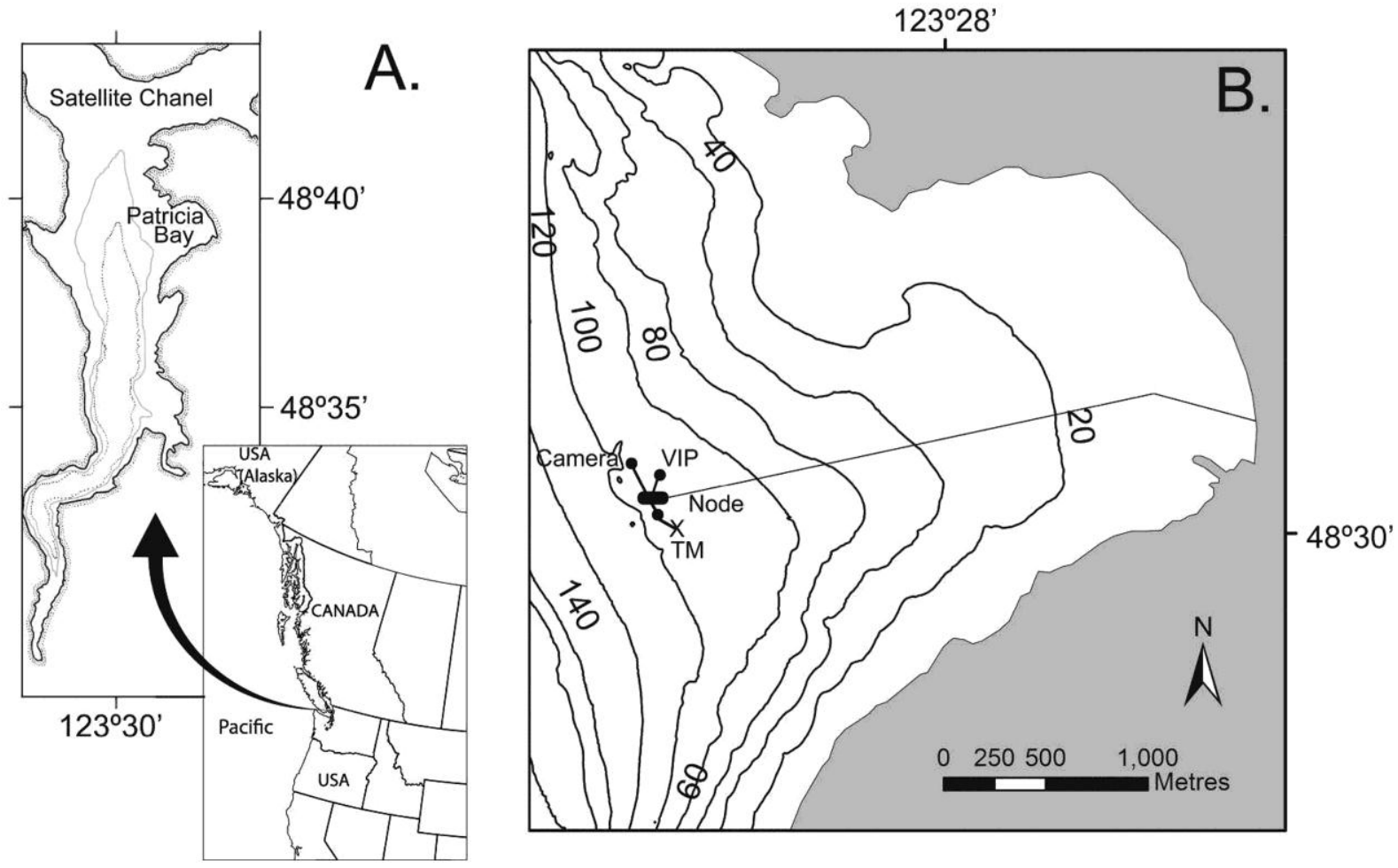
Fig. 2.Schematic of the TEMPO-mini ecological module setup during its deployment between September 2008 and February 2009 on the VENUS network at 97 m depth in Saanich Inlet (British Columbia, Canada; courtesy of P. Rodier, Ifremer).

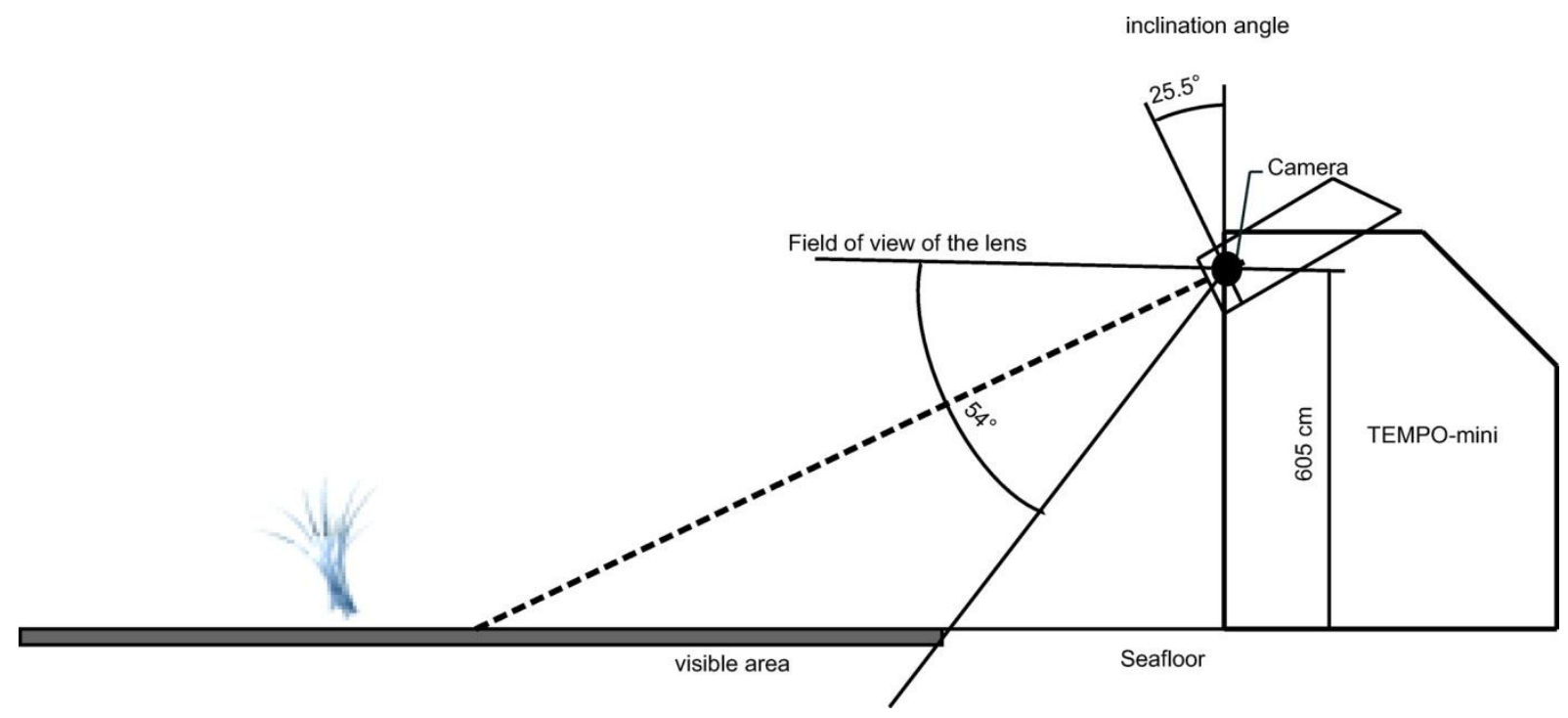

Fig. 3.Photo of the study area at the TEMPO-mini location in Saanich Inlet (British Columbia, Canada) showing the perspective grid. The optode is visible on the left. Two Metridium farcimen anemones, three Munida quadrispina (squat lobsters), and several Suberitidae sponges are present in the image.

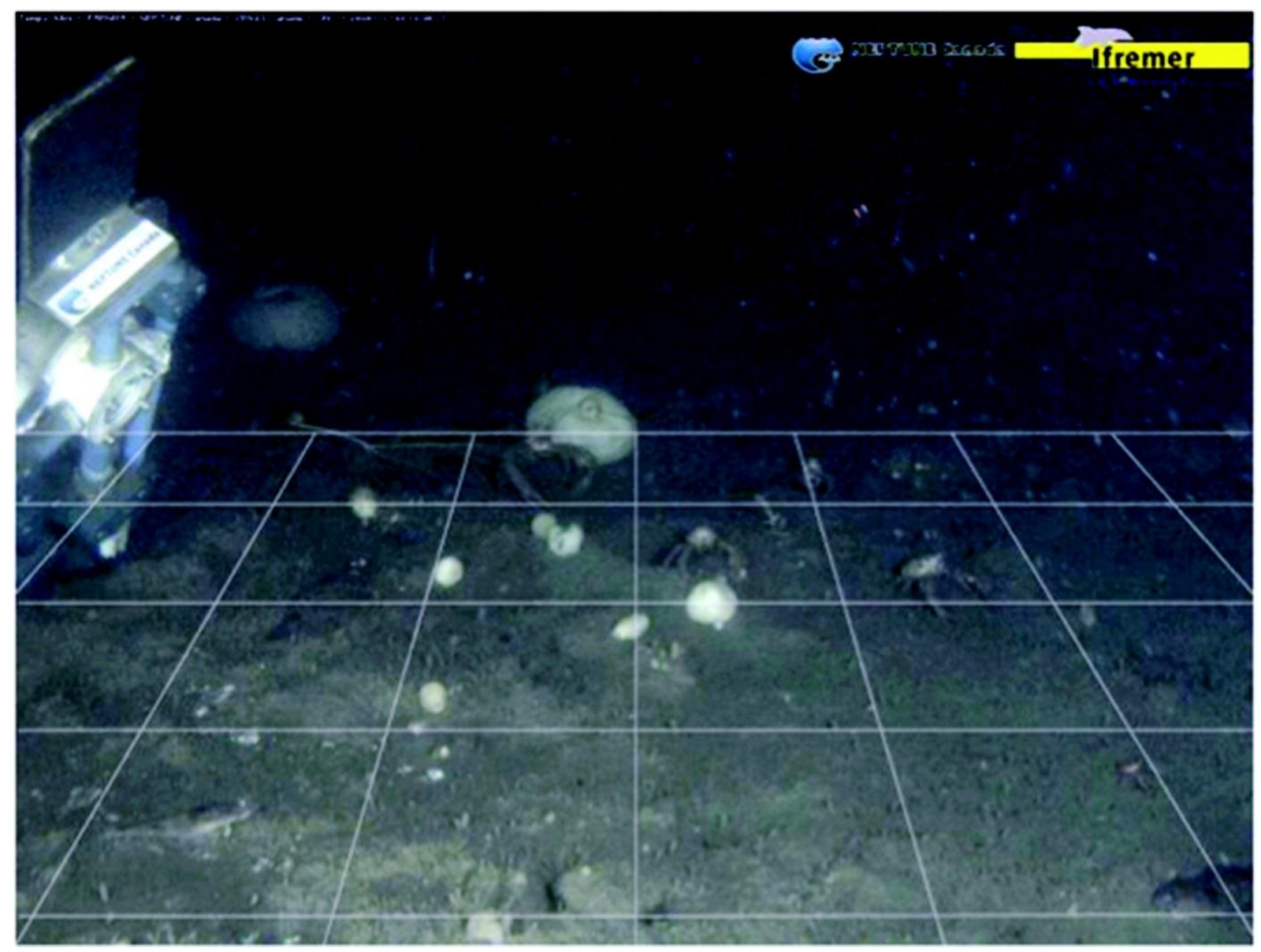


Fig. 4.Temporal variations of environmental conditions at the VENUS Instrument Platform (VIP) at $97 \mathrm{~m}$ in Saanich Inlet (British Columbia, Canada).
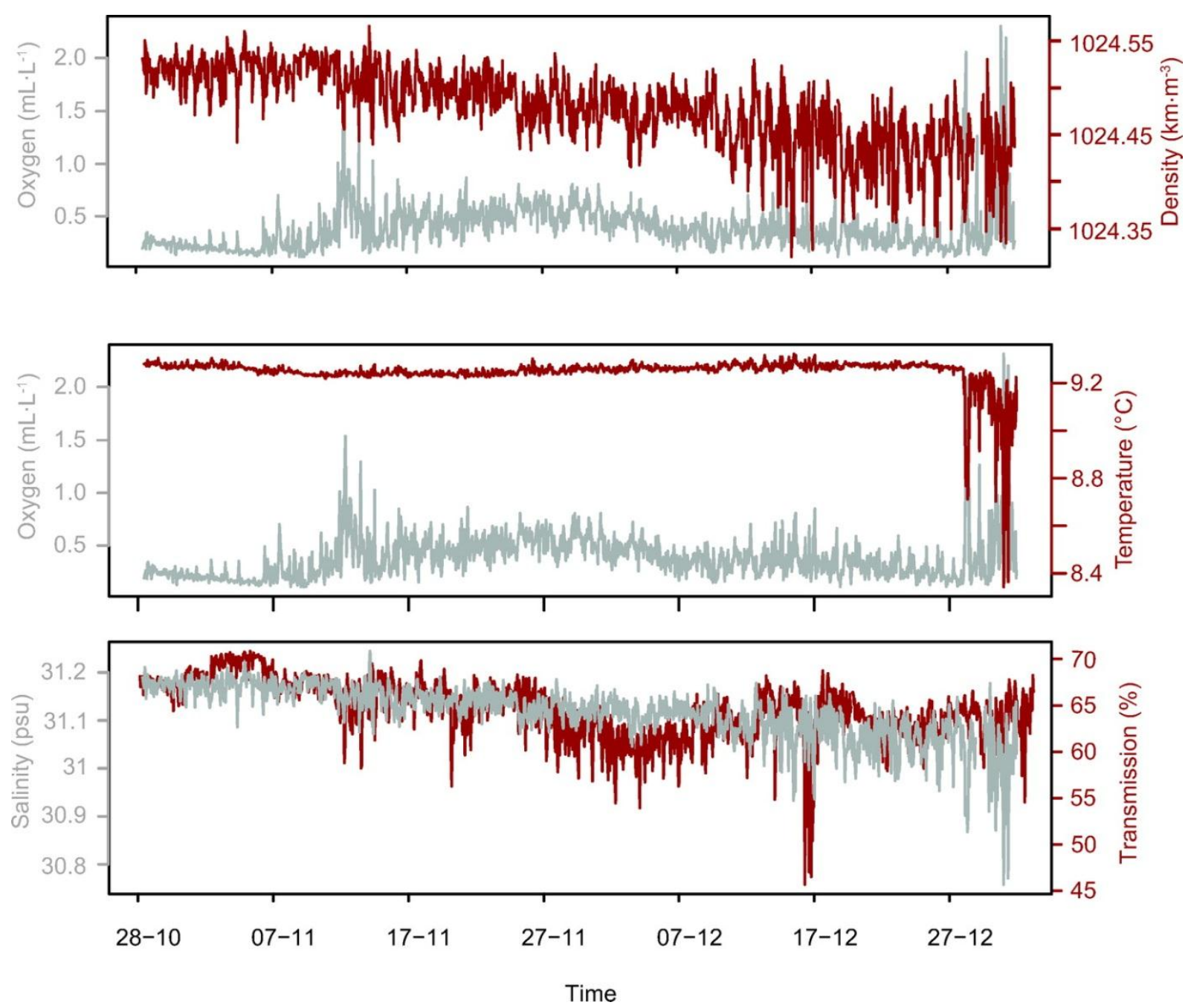
Fig. 5.Whittaker-Robinson periodograms performed on detrended environmental data $(n=$ 1381). Black dots represent significant $(p=0.05)$ periodicities and with the period value indicated above.
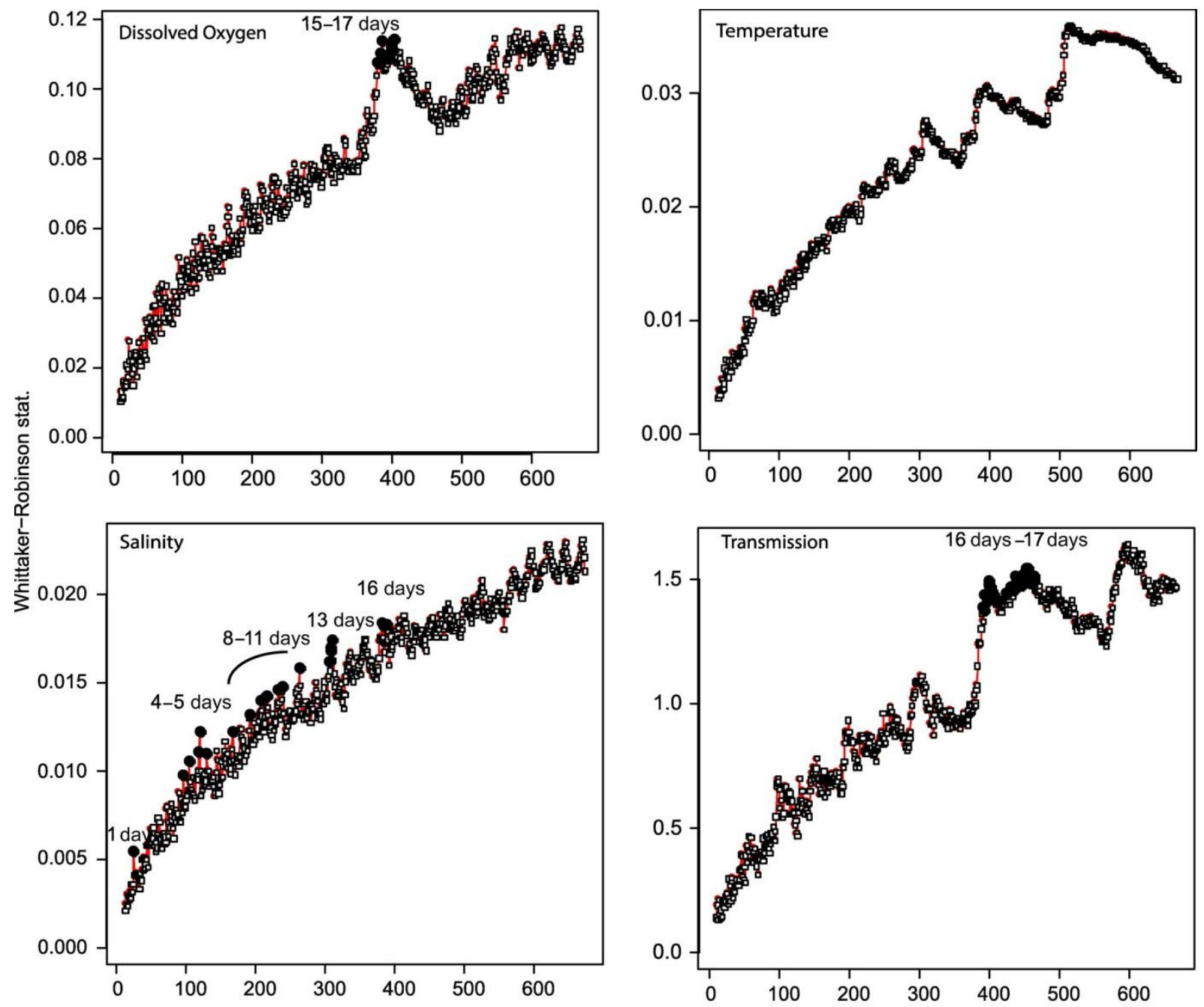

Period (hours) 
Fig. 6.Densities of the species encountered in the field of view of the camera in Saanich Inlet (British Columbia, Canada). The three lower panels represent moving averages (window = 12, i.e., 24 h).

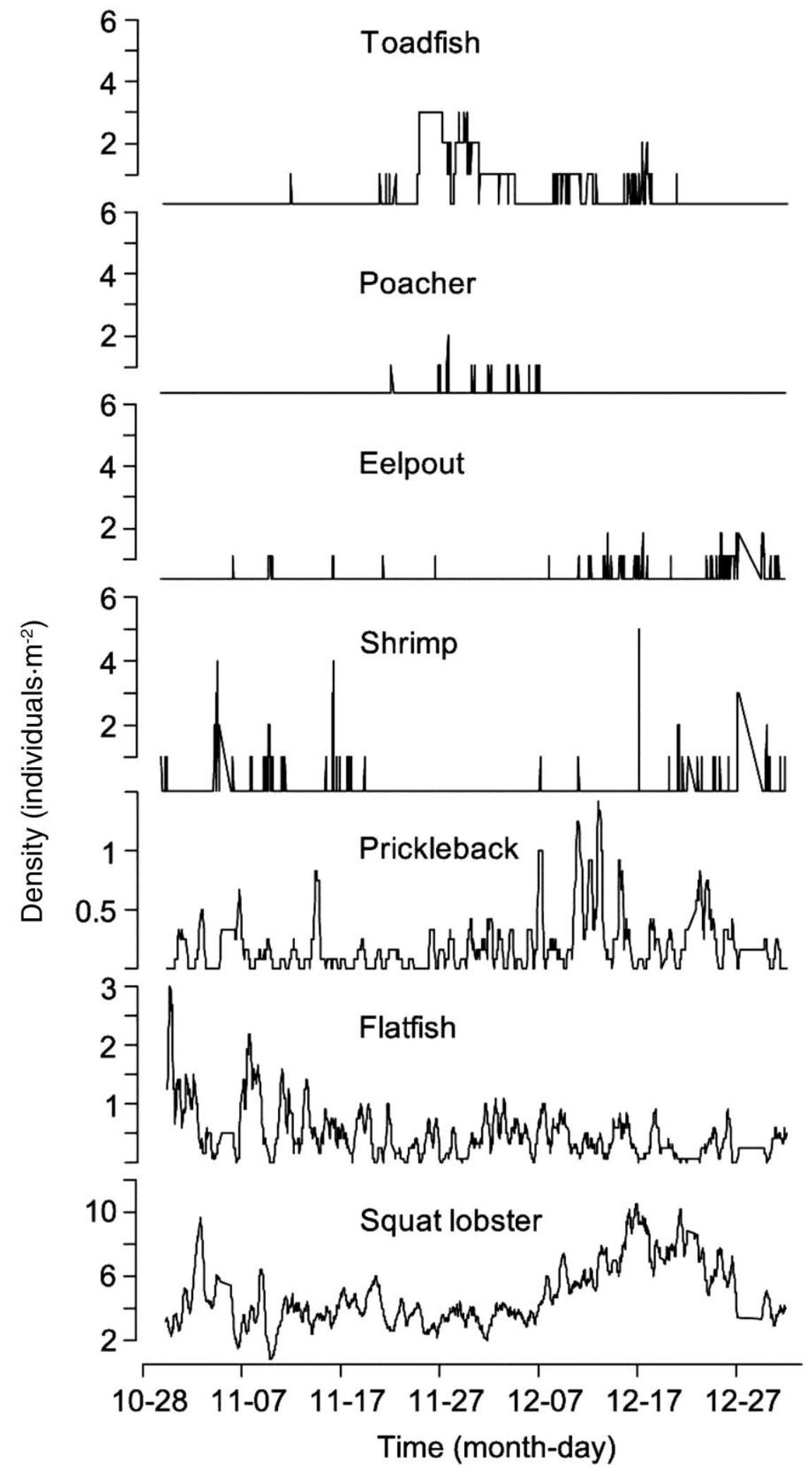


Fig. 7.Selected periodogram results performed on quantitative and qualitative biological data $(n=1381)$ extracted from video imagery. The three upper graphs show the WhittakerRobinson periodograms on density data, and the two lower panels show the contingency periodograms on anemones' behaviour. Black dots (three upper panels): significant ( $p=$ $0.05)$ periodicities with the period value; grey line (two lower panels): $95 \%$ confidence limit.
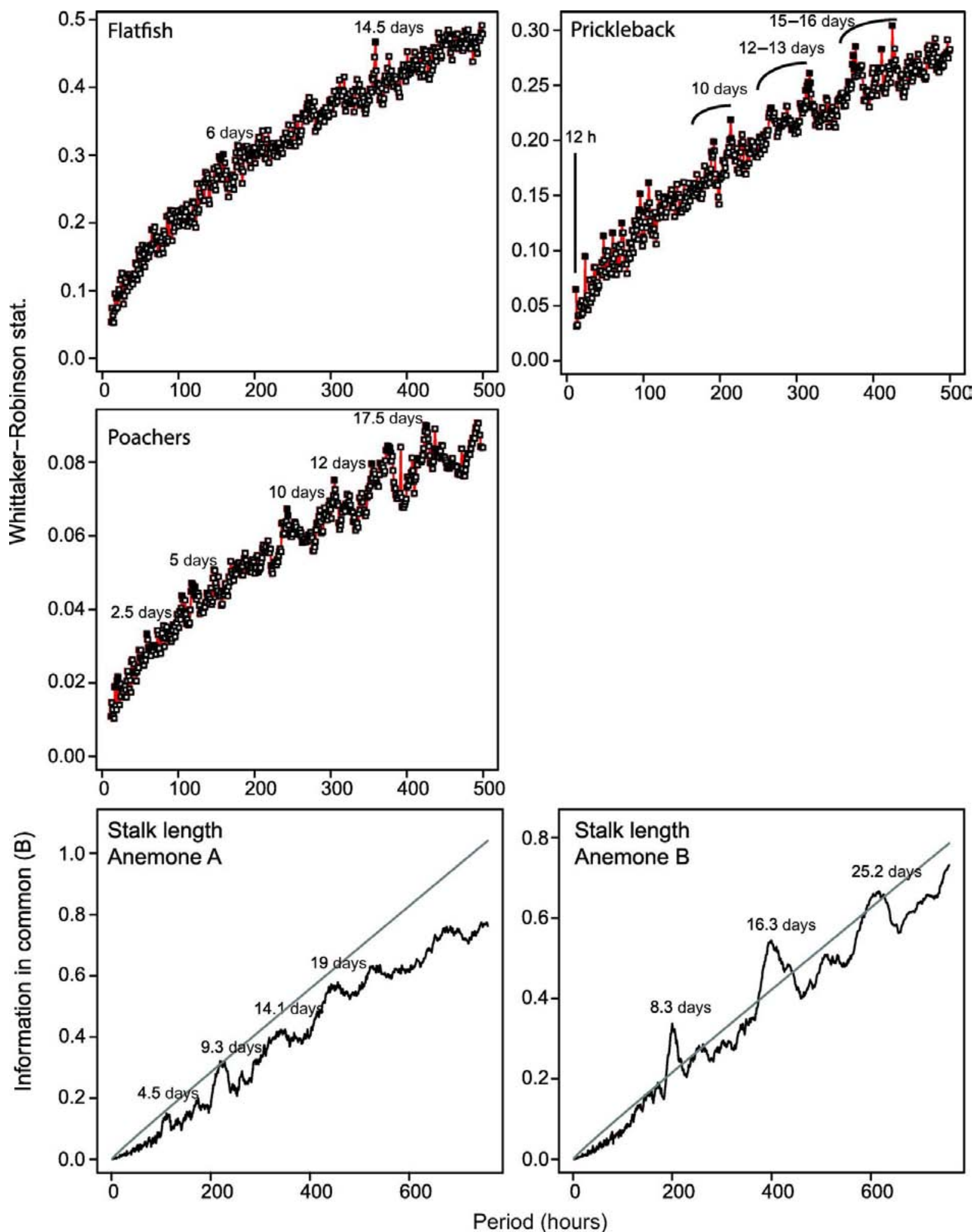
Fig. 8.Multivariate regression trees computed on environmental variables (A) and species density data (B) and constraint along the temporal gradient. Each leaf of the tree is characterized by the number of observations in that group and the explanatory variable value (date). Histograms represent the mean value of each variable (standard score) $(A)$ and each species (B) in that group. For the coloured version of this figure, refer to the Web site at http://www.nrcresearchpress.com/doi/full/10.1139/cjfas-2013-0611.

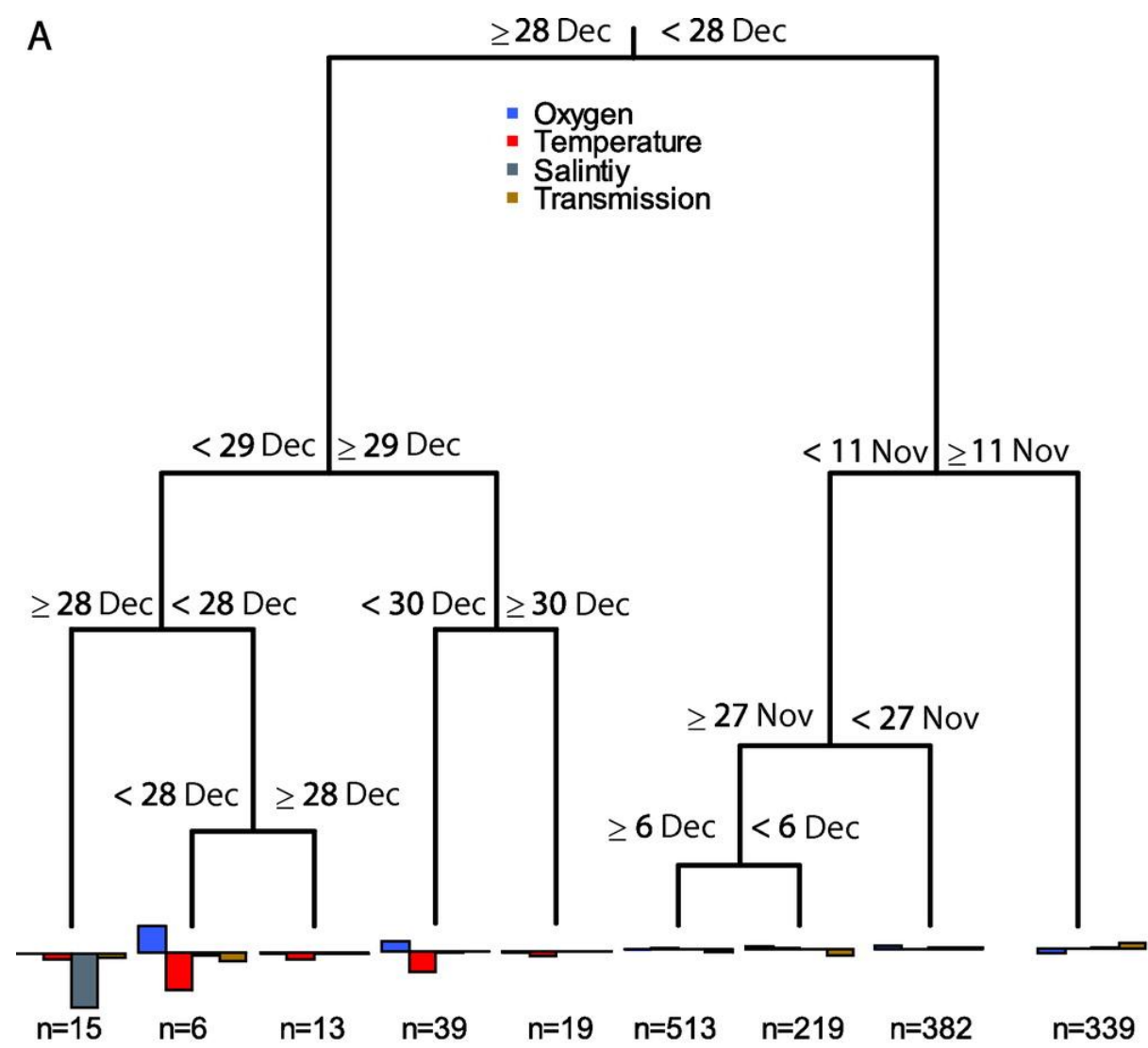

Error : 0.35 CV Error : 0.451 SE : 0.056

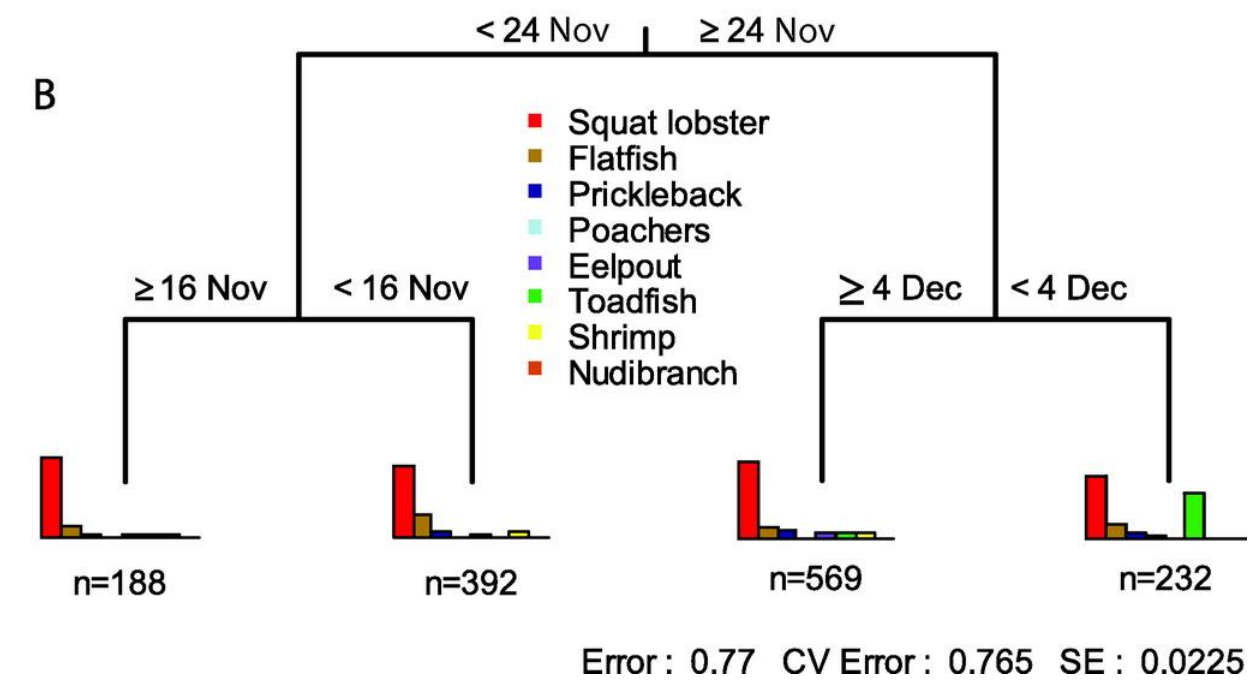


Fig. 9.Redundancy analysis biplot showing the species (light lines) and environmental variables (dark lines) correlations in Saanich Inlet (British Columbia, Canada). The percentage of variance explained by each canonical axe is indicated in brackets. The redundancy analysis is based on the nondetrended species density data. Data include the following: Oxygen, dissolved oxygen concentration $\left(\mathrm{mL} \cdot \mathrm{L}^{-1}\right)$; Salinity (psu); Temp, temperature $\left({ }^{\circ} \mathrm{C}\right)$; Transmission (\%); Eel, eelpout; Ff, flatfish; Pb, prickleback; Po, poachers;

Sh, shrimp; SI, squat lobster; and Td, toadfish.

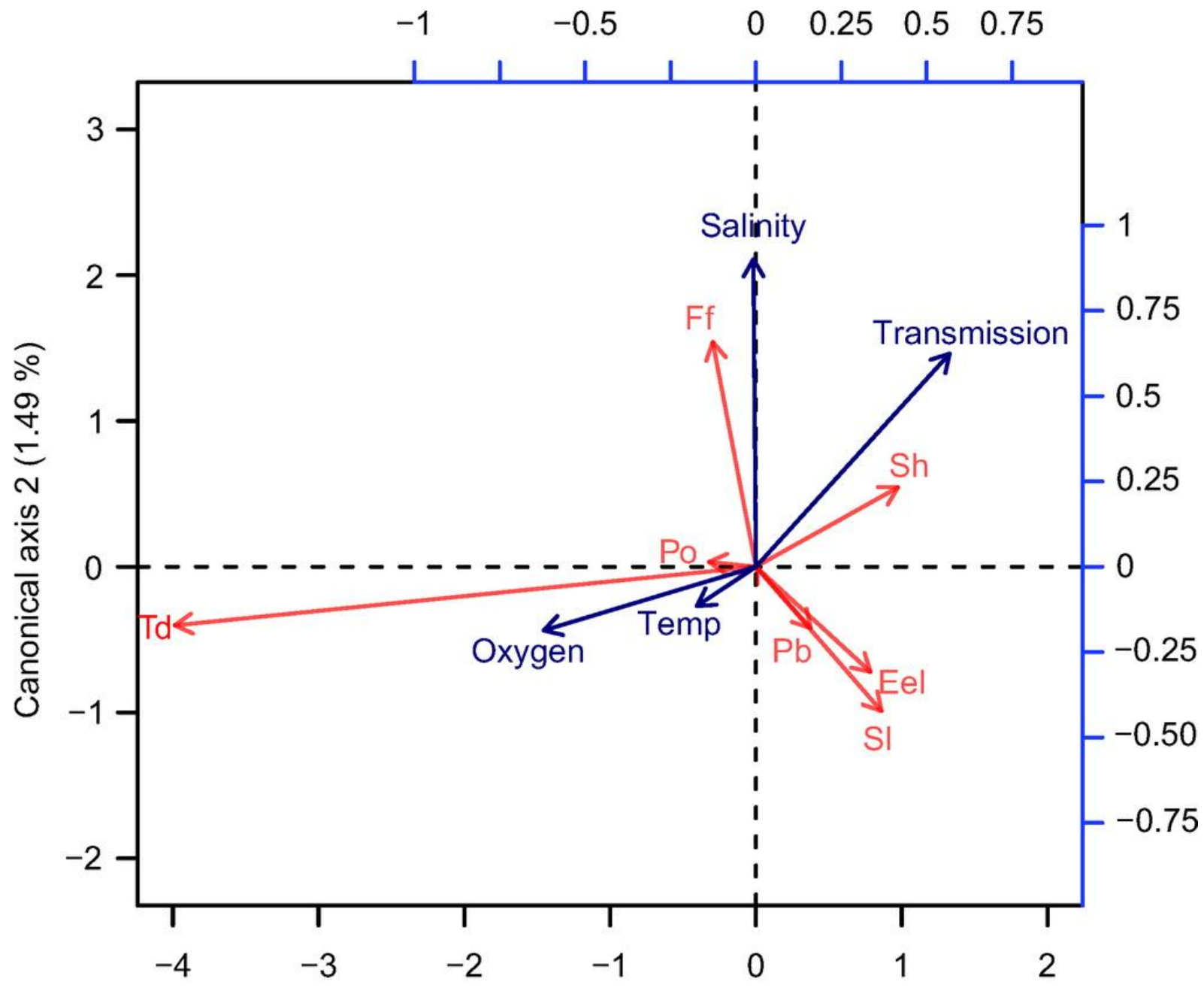

Canonical axis $1(6.05 \%)$ 
Table 1. Information extracted from the images acquired with the TEMPO-mini observatory module between 30 October and 31 December 2008 at $97 \mathrm{~m}$ depth in Saanich Inlet (British Columbia, Canada).

\begin{tabular}{|c|c|c|c|}
\hline Video information & Extracted data & Time period, frequency & Semiquantitative index details \\
\hline \multirow[t]{2}{*}{ Species distribution } & Presence-absence & Entire clip, hourly & $\begin{array}{l}\text { Presence: } 1 \\
\text { Absence: } 0\end{array}$ \\
\hline & Density & At 30th second, hourly & No. of individuals $\cdot \mathrm{m}^{-2}$ \\
\hline \multirow[t]{8}{*}{ Anemone behaviour } & Stalk extension & Entire clip, hourly & $\begin{array}{l}\text { Stalk extension: } \\
0: \text { not extended } \\
\text { 1: minimum length, anemone deployed } \\
\text { 2: intermediate length } \\
\text { 3: maximum length }\end{array}$ \\
\hline & Tentacle orientation & & Tentacle orientation: \\
\hline & & & $0:$ closed \\
\hline & & & 1: upwards \\
\hline & & & 2: on the right \\
\hline & & & 3: towards camera \\
\hline & & & 4: on the left \\
\hline & & & 5: towards the back \\
\hline \multirow[t]{6}{*}{ Zooplankton abundance } & Density estimates with indices & Between the 25th and & $0:$ no individuals \\
\hline & & 30th second, hourly & 1: $1-4$ individuals \\
\hline & & & 5: 5-9 individuals \\
\hline & & & 10: 10-29 individuals \\
\hline & & & 30: $30-49$ individuals \\
\hline & & & 50: 50 or more individuals \\
\hline \multirow[t]{4}{*}{ Squat lobster nutrition } & Nutrition reported using index & Entire clip & 0 : no nutrition \\
\hline & & & $\begin{array}{l}\text { 1: deposit-feeding using maxillipeds at } \\
\text { the sediment surface }\end{array}$ \\
\hline & & & 2: predation on zooplankton \\
\hline & & & 3: foraging \\
\hline \multirow[t]{2}{*}{ Species interactions } & Type of interactions reported & Entire clip & Intraspecific: 0 \\
\hline & using index & & Interspecific: 1 \\
\hline Comments & Other biotic observations & Entire clip & Animal behaviour \\
\hline $\begin{array}{l}\text { Environmental } \\
\text { conditions }\end{array}$ & Any relevant observations & Entire clip & e.g., current speed, suspension event \\
\hline
\end{tabular}

Note: Each video clip lasted 3 min.

Table 2. Kendall's $\tau$ correlation coefficients among benthic species $(\mathrm{df}=1380$, above diagonal) and their associated $p$ value (below diagonal) at $97 \mathrm{~m}$ depth in Saanich Inlet (British Columbia, Canada).

\begin{tabular}{lllllllll}
\hline & Squat lobster & Flatfish & Prickleback & Poacher & Eelpout & Toadfish & Shrimp & Nudibranch \\
\hline Squat lobster & & $-0.12^{* *}$ & $0.06^{* *}$ & $-0.09^{* *}$ & $0.07^{* *}$ & $-0.09^{* *}$ & 0.00 & -0.02 \\
Flatfish & 0.000 & & -0.03 & -0.03 & $-0.08^{* *}$ & $-0.05^{*}$ & $-0.05^{*}$ & 0.02 \\
Prickleback & 0.005 & 0.199 & & 0.01 & 0.02 & 0.03 & -0.04 & -0.02 \\
Poacher & 0.000 & 0.243 & 0.767 & & -0.04 & $0.13^{* *}$ & -0.04 & -0.01 \\
Eelpout & 0.002 & 0.002 & 0.503 & 0.182 & & $-0.10^{* *}$ & $0.07^{* *}$ & -0.01 \\
Toadfish & 0.000 & 0.038 & 0.184 & 0.000 & 0.000 & & $-0.13^{* *}$ & -0.02 \\
Shrimp & 0.873 & 0.040 & 0.091 & 0.189 & 0.007 & 0.000 & & -0.01 \\
Nudibranch & 0.431 & 0.454 & 0.535 & 0.854 & 0.703 & 0.430 & 0.708 & \\
\hline
\end{tabular}

Note: ${ }^{*}$, significant at $p=0.05 ; " *$, significant at $p=0.01$. 
Table 3. Adjusted $R^{2}$ and probabilities related to the temporal analysis of detrended species density data in Saanich Inlet (British Columbia, Canada) based on 1381 observations.

\begin{tabular}{llllll}
\hline & All & $\begin{array}{l}\text { Broad } \\
(14.5 \text { days })\end{array}$ & $\begin{array}{l}\text { Medium } \\
(5-6 \text { days })\end{array}$ & $\begin{array}{l}\text { Small } \\
(2-3 \text { days })\end{array}$ & $\begin{array}{l}\text { Fine } \\
(\sim 23 ~ h)\end{array}$ \\
\hline$R^{2}$ submodel on community & - & 0.195 & 0.087 & 0.057 & 0.024 \\
$R^{2}$ env on submodel & - & 0.203 & 0.063 & 0.006 & NS \\
$R^{2}$ env on community & $0.064^{* *}$ & 0.040 & 0.005 & 0.000 & - \\
Dissolved oxygen (mL.L $\left.{ }^{-1}\right)$ & $0.034^{* *}$ & $0.110^{* *}$ & $0.0123^{* *}$ & $0.003^{*}$ & - \\
Salinity (psu) & $0.009^{* *}$ & $0.009^{* *}$ & $0.041^{* *}$ & NS & - \\
Temperature $\left({ }^{\circ} \mathrm{C}\right)$ & $0.016^{* *}$ & $0.046^{* *}$ & $0.008^{* *}$ & $0.003^{*}$ & - \\
Transmission $(\%)$ & $0.014^{* *}$ & $0.050^{* *}$ & $\mathrm{NS}$ & $0.002^{*}$ & - \\
\hline
\end{tabular}

Note: First line: adjusted $R^{2}$ of each temporal submodel. Second line: adjusted $R^{2}$ of the submodel fitted values (linear combinations) and the environmental variables. Third line: product of the two first representing the variation of species data explained by the environmental data at each scale considered. Lower four lines of table: adjusted $R^{2}$ of each environmental variable in each submodel. ${ }^{*}$, significant at $p=0.05 ; "$, , significant at $p=0.01$. 